\title{
Circulação estacionária e estratificação de sal em canais estuarinos: simulação com modelos analíticos
}

\author{
(Stationary circulation and salt stratification in estuarine channels: \\ simulation with analitic models)
}

\author{
Marcos Eduardo Cordeiro Bernardes' \& Luiz Bruner de Miranda ${ }^{2}$

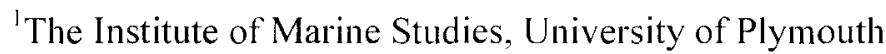 \\ (Drake Circus, Plymouth - PL 4 8AA, United Kingdom) \\ ${ }^{2}$ Instituto Oceanográfico da Universidade de São Paulo, São Paulo, Brasil \\ (Caixa Postal 66149, 05315-970 São Paulo, SP, Brasil)
}

- Abstract: The stationary circulation and salinity stratification in the southern region of CananéiaIguape Estuarine-lagoon System and Bertioga Channel are described. The models of Fisher et al. (1972), Prandle (1985) and Miranda (1998) were selected for the simulation of vertical profiles of the longitudinal component of velocity and salinity. The experimental data set used for the calibration of these models were sampled in 41 anchored stations, for one or two semidiurnal tidal cycles. For well mixed and partially mixed conditions, theoretical results and experimental data were in close agreement. The longitudinal density gradient and the river flow were the most important forcing for the stationary circulation and salt stratification. The wind stress had a secondary importance. According to the Stratification-circulation diagram of Hansen \& Rattray (1966), the southern region of Cananéia estuarine system presented well-mixed conditions (Type 1a) and partially mixed conditions (Type 2b), before and after the destruction of the Valo Grande dam, respectively. The Bertioga Channel presented partially mixed conditions (Type 2b) next to the Itapanhaú River and well mixed conditions (Type 1b) in other along-channel positions. The theoretical turbulent viscosity coefficients were similar to those calculated by Mesquita et al. (1992).

- Resumo: A circulação estacionária e a estratificação de sal na região sul do Sistema Estuarino-lagunar de Cananéia-Iguape e no Canal de Bertioga são descritas. Os modelos de Fisher et al. (1972), Prandle (1985) e Miranda (1998) foram escolhidos para a simulação dos perfis verticais do componente longitudinal da velocidade e da salinidade. Os dados experimentais utilizados na calibração desses modelos foram amostrados em 41 estações fixas de um ou dois ciclos de maré semidiurna. Os modelos reproduziram com boa fidelidade condições experimentais bem misturadas e parcialmente misturadas. O gradiente longitudinal de densidade e a descarga de água doce foram as principais forçantes da circulação estacionária e estratificação de sal, em detrimento da influência secundária da tensão de cisalhamento do vento. De acordo com o diagrama Estratificação-circulação de Hansen \& Rattray (1966), a região sul do sistema estuarino de Cananéia apresentou condições bem misturadas (Tipo 1a) e parcialmente misturadas (Tipo 2b) antes e depois do rompimento da barragem do Valo Grande, respectivamente. No Canal de Bertioga foram observadas condições parcialmente misturadas (Tipo 2b) nas imediações do Rio Itapanhaú e bem misturadas (Tipo lb) no restante do canal. Os coeficientes teóricos de viscosidade turbulenta foram similares aos calculados experimentalmente por Mesquita et al. (1992).

- Descriptors: Partially mixed, Velocity, Salinity, Stratification-circulation parameters, Eddy viscosity and diffusion, Bertioga, Cananéia.

- Descritores: Parcialmente misturados, Velocidade, Salinidade, Parâmetros estratificação-circulação, Viscosidade turbulenta, Difusão turbulenta, Bertioga, Cananéia.

Contr. $n^{\circ} 844$ do Inst. oceanogr. da Usp.

\section{Introdução}

Os estuários são ambientes bastante favoráveis à presença humana e ao crescimento de centros urbanos. Neste trabalho foram selecionados dois sistemas estuarinos do litoral do estado de São Paulo, Brasil, de características bastante distintas com relação à ocupação humana que se dá em seus entornos: o Sistema Estuarino-lagunar de Cananéia-Iguape, com sua biodiversidade relativamente preservada e o Canal 
de Bertioga, situado nas proximidades do complexo industrial e portuário da Baixada Santista (Fig. 1a).

A hipótese científica que orienta este trabalho é: as circulações estacionárias do extremo sul do Sistema Estuarino-lagunar de Cananéia-Iguape e do Canal de Bertioga são condicionadas basicamente pelas seguintes forçantes: a descarga fluvial, o gradiente longitudinal de salinidade e a tensão de cisalhamento do vento.

Com base nessa hipótese e através da utilização de dados experimentais e modelos analíticos, este trabalho pretende descrever a circulação estacionária dos dois sistema estuarinos. Entre os objetivos específicos incluem-se: i) simular e aferir quali-quantitativamente os perfis verticais estacionários do componente longitudinal de velocidade (u) e de salinidade (S), com diferentes modelos analíticos; ii) determinar a importância de cada uma das forçantes que influenciam a circulação estacionária; iii) avaliar a variabilidade espaço-temporal a que estão sujeitos esses sistemas estuarinos, e; iv) estimar valores médios para os coeficientes efetivos de viscosidade e difusão turbulenta de sal.

\section{Áreas de estudo}

O Sistema Estuarino-lagunar de CananéiaIguape está localizado no extremo sul do Estado de São Paulo, entre as coordenadas $24^{\circ} 35^{\prime} \mathrm{S}$; $047^{\circ} 30^{\prime} \mathrm{W}$ e $25^{\circ} 10^{\prime} \mathrm{S}$; $048^{\circ} 05^{\prime} \mathrm{W}$ (Fig. 1a), apresentando cerca de $100 \mathrm{~km}$ de extensão. Ele é composto por um complexo sistema de corpos de água que circundam quatro ilhas: de Iguape, Comprida, de Cananéia onde se situa a cidade de mesmo nome - e Ilha do Cardoso. Os corpos de água mais importantes são: Rio Ribeira do Iguape, Mar Pequeno, Mar de Cananéia, Mar de Itapitangui, Mar de Cubatão e Baía do Trapandé. A área superficial total desses canais

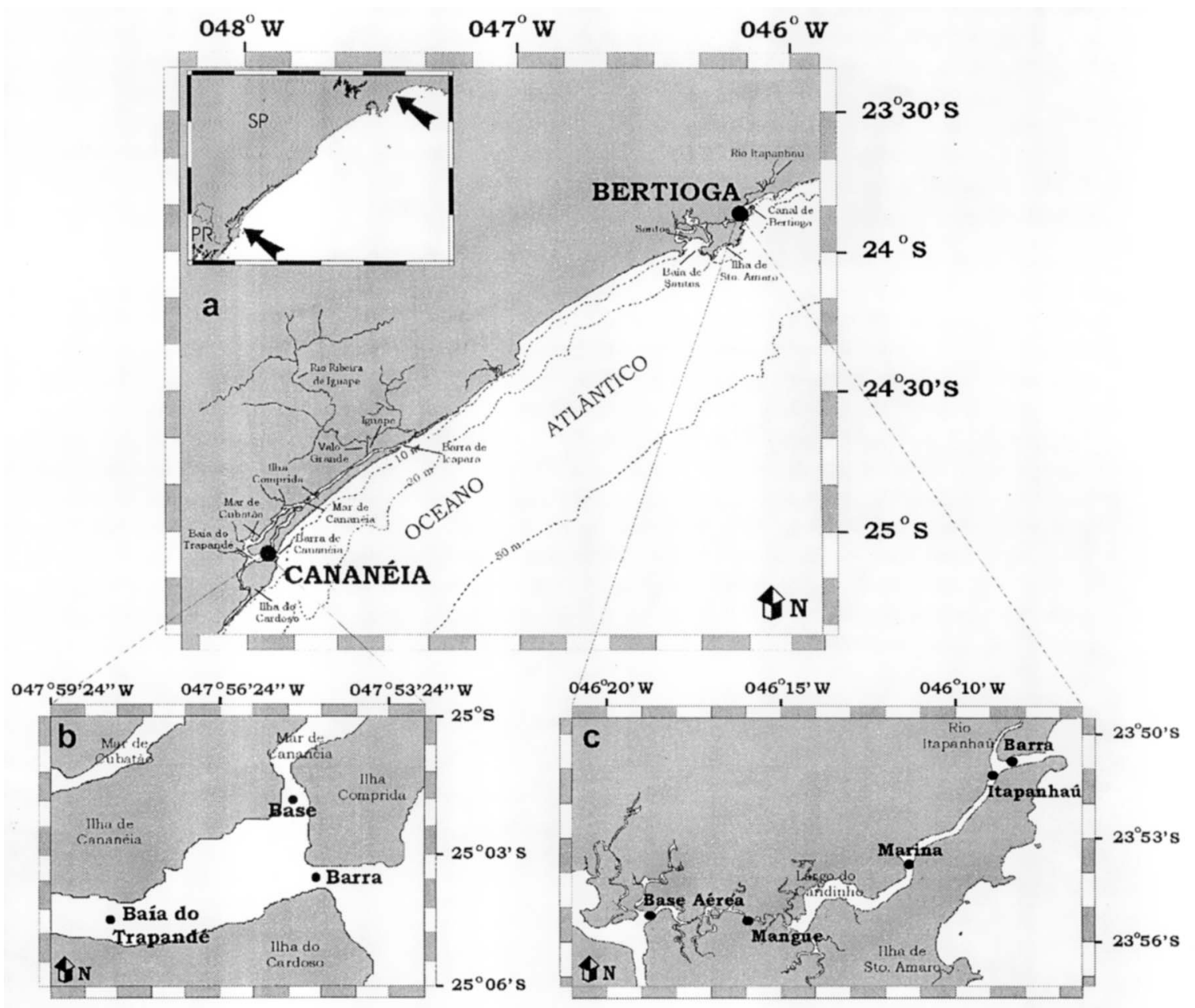

Fig. 1. Localização das áreas de estudo (a) e posição das estações oceanográficas $(\bullet)$ na região sul do sistema estuarinolagunar de Cananéia-Iguape (b) e no canal de Bertioga (c). 
que compõem o sistema é de aproximadamente 115 $\mathrm{km}^{2}$ (Miyao et al., 1986). A principal comunicação do sistema com a região costeira é através das Barras de Cananéia e de Icapara, próximo à cidade de Iguape. A entrada da Barra de Cananéia tem largura próxima a $3.700 \mathrm{~m}$ (Fig. 1b), topografia do fundo muito irregular com bancos arenosos submersos a menos de três metros da superfície, que constituem grande obstáculo para a navegação. Em direção ao interior do sistema, a largura do canal de entrada é reduzida para aproximadamente $1.040 \mathrm{~m}$ onde é observada a maior profundidades $(\cong 22 \mathrm{~m})$ de todo sistema estuarino devido ao efeito erosivo de fortes correntes.

A largura máxima da Baía do Trapandé é de $3.200 \mathrm{~m}$, com afunilamento da mesma para aproximadamente $2.000 \mathrm{~m}$ em direção ao Mar de Cubatão. $\mathrm{Na}$ região norte (parte insular da Ilha de Cananéia) existe um grande baixio, geralmente emerso na maré baixa. Suas profundidades são geralmente menores do que $6 \mathrm{~m}$ na maré baixa, mas há registros de uma depressão com cerca de $10 \mathrm{~m}$ nas proximidades da Ilha do Cardoso. A região sul do Mar de Cananéia apresenta a forma $\mathrm{S}$ alongada e na sua porção mais estreita $(500 \mathrm{~m})$ ocorrem depressões com profundidade de até 15 metros.

A feição topográfica submersa dessa região foi estudada com base na elaboração de um modelo digital por Bonetti Filho \& Furtado (1996), confirmando as diferentes características da topografia de fundo e a identificação da formação de um delta de vazante na Barra de Cananéia, que justifica a ocorrência de baixas profundidades na entrada.

Atualmente, o aporte fluvial no sistema estuarino-lagunar ocorre principalmente através do rio Ribeira de Iguape, cuja área de drenagem é de aproximadamente $23.350 \mathrm{~km}^{2}$. Uma contribuição secundária, aqui denominada de bacia de drenagem local, também ocorre através dos rios Taquari, Mandira, das Minas e Itapitangui que juntos drenam uma área em torno de $1339 \mathrm{~km}^{2}$ (Mishima et al., 1985). Por volta do ano de 1841 foi construído um estreito canal (Vala do Rocio), com largura média de $4,4 \mathrm{~m} \mathrm{e} 2,6 \mathrm{~km}$ de comprimento, ligando o Rio Ribeira de Iguape ao Mar Pequeno (Fig. 1a). No decorrer das décadas seguintes a ação da erosão em suas margens ocasionou o alargamento gradativo do canal que atingiu até 1965 a largura média de $192,7 \mathrm{~m}$ (GEOBRÁS, 1966), sendo atualmente denominado Valo Grande.

Entretanto, em 1978, quando cerca de $70 \%$ da vazão do Rio Ribeira de Iguape se dava através do Valo Grande (Teles \& Suguio, 1997)*, foi construída

(*) Teles, A. P. S. da S. \& Suguio, K. 1997. Possível impacto da abertura do Valo Grande no complexo estuarino-lagunar de Iguape SP/BR. In: CONGRESSO DA ASSOCIAÇÃO BRASILEIRA DE ESTUDOS DO QUATERNÁRIO / REUNIÃO SOBRE O QUATERNÁRIO DA AMÉRICA DO SUL, 6. Curitiba, 1997. Resumos expandidos. Curitiba, ABEQUA. p. 151-154. uma barragem para restabelecer o seu antigo curso; nessa época, a área de drenagem continental ficou restrita à da bacia de drenagem local. Essa situação perdurou até janeiro de 1995 , quando chuvas intensas destruíram grande parte da barragem e uma parcela substancial da vazão do rio voltou a desaguar novamente no Mar Pequeno. Segundo GEOBRÁS (1966), a vazão total média dessa bacia era da ordem de $50 \mathrm{~m}^{3} \mathrm{~s}^{-1}$. DAEE (1987) estimou uma descarga bem menor de aproximadamente $3 \mathrm{~m}^{3} \mathrm{~s}^{-1}$. Mais recentemente, Bonetti Filho \& Miranda (1997) obtiveram, por meio de diferentes métodos indiretos, vazões médias de $43 \mathrm{~m}^{3} \mathrm{~s}^{-1}$ e $91 \mathrm{~m}^{3} \mathrm{~s}^{-1}$. Também através de cálculos indiretos, Bérgamo (2000) estimou as seguintes vazões médias totais das bacias de drenagem do Ribeira de Iguape e local: antes do rompimento da barragem, a descarga média anual seria de aproximadamente $47 \mathrm{~m}^{3} \mathrm{~s}^{-1}$, enquanto após a ruptura da barragem esse aporte teria aumentado para $774 \mathrm{~m}^{3} \mathrm{~s}^{-1}$.

A maior parte dos estudos de oceanografia física no complexo-estuarino-lagunar de Cananéia foi realizada nas imediações da Barra de Cananéia e no Mar de Cananéia, que foi caracterizado por Miyao (1977), Miyao et al. (1986) e Miyao \& Harari (1989) como um canal raso, fracamente estratificado e forçado por marés semidiurnas. De acordo com a classificação proposta por Cameron \& Pritchard (1963) e Officer (1977), o Mar de Cananéia foi considerado como do tipo parcialmente misturado (Bonetti Filho, 1995 e Miranda et al., 1995). Devido à pequena razão entre a amplitude da maré e a profundidade média, foi caracterizada pela dominância de maré de vazante (Bonetti Filho, 1995 e Miyao \& Harari, 1989). Ao analisar a circulação e os processos de mistura numa estação fixa no Mar de Cananéia, sob condições de sizígia antes do rompimento da barragem do Valo Grande, Miranda et al. (1995) e Bonetti Filho (1995) observaram que aproximadamente todo o fluxo de sal estuário acima foi ocasionado por difusão turbulenta, enquanto a advecção tinha uma contribuição praticamente desprezivel para esse fluxo.

Com base na aplicação de um modelo analítico bidimensional e na análise do comportamento da velocidade longitudinal média, ao longo de ciclos de maré, Miranda (1990) e Miranda \& Castro (1996) identificaram, sob condições estacionárias, que as principais forçantes foram o gradiente longitudinal de salinidade e a descarga de água doce. Com o modelo analítico ajustado, Miranda (1990) concluiu que os melhores resultados foram obtidos sob condições de ausência de vento e de baixa descarga fluvial $\left(50 \mathrm{~m}^{3} \mathrm{~s}^{-1}\right)$. Já em Miranda et al. (1995), os resultados mostraram que a circulação foi forçada principalmente pela maré, atribuindo-se ao componente baroclínico da força de gradiente de pressão apenas um efeito secundário. 
A região sul do Mar de Cananéia, antes do rompimento da barragem do Valo Grande, foi classificada como Tipo 2a (fraca estratificação vertical e amplo domínio $\cong 100 \%$ da difusão turbulenta sobre o transporte de sal estuário acima). Após o rompimento da barragem, a região tornou-se Tipo $2 b$, porém com maior estratificação vertical e influência do processo advectivo sobre o transporte de sal, chegando a 50\% nas épocas de grande descarga fluvial. Após o rompimento da barragem do Valo Grande, a Barra de Cananéia e a Baía do Trapandé também foram classificadas como Tipo $2 b$, com o transporte de sal da primeira sendo influenciado quase que igualmente pela advecção e pela difusão turbulenta (50\%), enquanto na segunda a difusão turbulenta forçou aproximadamente $90 \%$ do transporte de sal (Miranda \& Castro, 1997*; Bérgamo, 2000).

O Canal de Bertioga está localizado na região da Baixada Santista, entre as coordenadas $23^{\circ} 51^{\prime} 30^{\prime \prime} \mathrm{S}$; $046^{\circ} 08^{\prime} \mathrm{W}$ e $23^{\circ} 55^{\prime} \mathrm{S}$; $046^{\circ} 18^{\prime} 30^{\prime \prime} \mathrm{W}$ (Fig. 1c). O canal apresenta duas extremidades livres: uma para o Oceano Atlântico, próximo à cidade de Bertioga e outra para o Canal de Piaçaguera, em Santos. A extensão do canal é de aproximadamente $25 \mathrm{~km}$, com profundidades de até $15 \mathrm{~m}$ na região da Barra de Bertioga e algumas depressões, com cerca de $10 \mathrm{~m}$, até o Largo do Candinho. Nesse largo observam-se as maiores larguras $(1.000 \mathrm{~m})$, enquanto que a oeste o canal sofre um acentuado estreitamento, chegando até cerca de $40 \mathrm{~m}$, que reduz significativamente os processos de troca entre os canais de Bertioga e Piaçaguera.

O aporte fluvial no Canal de Bertioga é bem inferior ao observado no complexo estuarino-lagunar de Cananéia-Iguape. Além de rios com descargas relativamente pequenas, destaca-se apenas a do Rio Itapanhaú que, com área da bacia de drenagem de aproximadamente $260 \mathrm{~km}^{2}$, é o principal responsável por esse aporte. A desembocadura desse rio a aproximadamente $2,5 \mathrm{~km}$ da barra e suas extremidades, boca a leste e a comunicação com o Canal de Piaçaguera a oeste (Fig. 1c), fazem com que as características geomorfológicas desse canal estuarino se desviem bastante daquela de um estuário clássico. Os dados de vazão desse rio são escassas, mas do acervo do Banco de Dados Fluviométricos do Estado de São Paulo, publicadas pelo Departameto de Águas e Energia Elétrica do Estado de São Paulo, observam-se variações de médias mensais mínimas de $1,0 \mathrm{~m}^{3} \mathrm{~s}^{-1}$, no inverno, e máximas de $8,8 \mathrm{~m}^{3} \mathrm{~s}^{-1}$ no verão.

Os estudos científicos na região ainda são bastante reduzidos, especialmente os que relacionam

(*) Miranda, L. B. de \& Castro, B. M. 1997. Classificação do mar de Cananéia e estimativa do fluxo de sal. In: CONGRESSO LATINO-AMERICANO SOBRE CIÊNCIAS DO MAR, 7. Santos, 1997. Resumos expandidos. Santos, IOUSP/ALICMAR/FIESP, 2:175-176. a circulação do canal a fatores bio-ecológicos. Entretanto, Gianesella et al. (2000) concluem que a maré e a descarga de água doce têm um efeito decisivo na disponibilidade de nutrientes e na distribuição de organismos fitoplanctônicos no interior do Canal de Bertioga.

O canal é forçado por marés mistas predominantemente semidiurnas, de amplitude moderada, podendo variar entre $0,73 \mathrm{~m}$ e $1,5 \mathrm{~m}$ (Fúlfaro \& Ponçano, 1976; Miranda et al., 1998). Com base em experimentos numéricos, Harari \& Camargo (1998) observaram que, devido à penetração da onda de maré no interior do canal através das duas extremidades, o "tombo das águas" ocorre nas imediações do Largo do Candinho. De acordo com a classificação proposta em Defant (1960), Miranda et al. (1998) obtiveram como número de forma $\left[\left(\mathrm{K}_{1}+\mathrm{O}_{1}\right) /\left(\mathrm{M}_{2}+\mathrm{S}_{2}\right)\right]$ o valor de 0,32 , indicando tratarse de maré do tipo semidiurna, mas caracterizada por significativa desigualdade diurna e uma considerável modulação quinzenal de acordo com a fase lunar.

Segundo a classificação proposta por Hansen \& Rattray (1966), Miranda et al. (1998) mostraram que, durante o experimento de inverno austral de 1991, a região próxima à desembocadura do Rio Itapanhaú foi classificada como parcialmente misturada, variando do Tipo $2 b$, sob condições de quadratura, para o Tipo $2 \mathrm{a}$, em sizígia. Na primeira condição os processos advectivo e de difusão turbulenta contribuíram $(\mathrm{u} \sim 0,5)$ para o transporte de sal estuário acima. Entretanto, na sizígia, o aumento do cisalhamento vertical da corrente intensificou a erosão do gradiente vertical de salinidade, diminuindo a estabilidade da coluna de água; em conseqüência, o parâmetro $v$ aumentou para 0,9 , indicando que $90 \%$ do transporte de sal passou a ser gerado por difusão turbulenta. Nesse experimento, também ficou caracterizada a mudança longitudinal da classificação do canal na quadratura, de parcialmente misturado na barra, para bem misturado no Largo do Candinho.

\section{Metodologia}

Os trabalhos de campo foram realizados em estações fixas durante um ou dois ciclos de maré, que nessas regiões é semidiurna (período de 12,6 h). Durante esse periodo, foram realizadas medições horárias de temperatura, salinidade, direção e intensidade da corrente na coluna de água, em intervalos regulares de profundidade. $O$ equipamento utilizado nas campanhas foi um sistema Valeport, modelo 108MkIII, com as seguintes resoluções: para as propriedades hidrográficas $\pm 0,002^{\circ} \mathrm{C}, \pm 0,003 \mathrm{mS}$ $\mathrm{cm}^{-1}, \pm 0,005 \%$ decibares (FS), e corrente $\pm 0,01 \mathrm{~m} \mathrm{~s}^{-1}$ e $\pm 0,25^{\circ}$. A medida mais próxima do fundo foi feita em torno de $1 \mathrm{~m}$ de distância e, posteriormente, extrapolada até o fundo; para a intensidade da velocidade no fundo, assumiu-se o princípio de 
aderência (atrito máximo) onde a velocidade experimental é considerada nula.

A fim de minimizar as influências das variações da maré na profundidade de coleta, optouse pela utilização da profundidade adimensional $\mathrm{Z}=\mathrm{z} / \mathrm{h}(\mathrm{t})[\mathrm{z}$ e $\mathrm{h}(\mathrm{t})$ denotam a profundidade de coleta $\mathrm{e}$ a espessura da coluna de água no instante das medidas, respectivamente], segundo metodologia proposta por Kjerfve (1975). As medidas foram interpoladas ao longo da coluna de água, desde a superfície até o fundo, em intervalos $\Delta \mathrm{Z}=\mathrm{Z} / 10$.

A representação gráfica dos resultados experimentais e dos obtidos com a aplicação de modelos analíticos, foi feita em relação ao referencial cartesiano ortogonal $(O x z)$, com o eixo Ox orientado para a boca do estuário. Apenas nas análises da estação Base de Cananéia o eixo $O x$ foi trocado por $O y$, que foi orientado no sentido do norte geográfico; em qualquer caso, o componente longitudinal de velocidade foi denotado por u. Por haver diferenças entre esses modelos em relação à origem e orientação do eixo vertical $(O z)$, os resultados foram apresentados com a origem no fundo do canal e com sentido oposto ao da aceleração da gravidade. O Sistema Internacional de Unidade (SI) foi adotado para expressar todas grandezas físicas.

Foram feitas médias temporais da temperatura, salinidade e intensidade do componente longitudinal da velocidade para cada décimo da profundidade adimensional durante ciclos completos de maré. A salinidade foi calculada com o algoritmo da Escala Prática de Salinidade, EPS-1978 (UNESCO, 1981). O processamento dos dados, conforme procedimento descrito acima, seguiu a metodologia apresentada em Kjerfve (1979).

Determinados os perfis verticais médios de $u$ e $\mathrm{S}$, foram calculados os respectivos desvios padrão ao longo do ciclo de maré, com nível de significância de 0,95 . Esse procedimento foi adotado para análise da variabilidade horária de $u$ e $\mathrm{S}$ em torno do valor médio dessas propriedades. Em seguida, foram realizados os ajustes dos perfis teóricos dessas propriedades aos experimentais.

Os resultados teóricos dos perfis verticais da velocidade residual e da salinidade foram gerados pelos modelos analíticos bidimensionais de Fisher et al. (1972) e Miranda (1998). A solução hidrodinâmica desses modelos considera o balanço estacionário incluindo o componente baroclínico da força de gradiente de pressão, o efeito da tensão de cisalhamento do vento $\mathrm{e}$ a descarga fluvial, assumindo o coeficiente cinemático de viscosidade turbulento $\left(\mathrm{N}_{\mathrm{z}}\right)$ constante. Por sua vez, a solução do processo de mistura para calcular perfis verticais estacionários de salinidade tem por base a equação de conservação de sal sob condição estacionária, considerando o balanço entre os transportes advectivo e difusivo de sal nas direções horizontal e vertical, assumindo constante o coeficiente cinemático de difusão turbulento de sal $\left(\mathrm{K}_{\mathrm{z}}\right)$.

$\mathrm{O}$ modelo hidrodinâmico de Fisher et al. (1972) considera como condição inferior de contomo o atrito máximo e o terceiro modelo utilizado (Prandle, 1985) determina apenas o perfil vertical da velocidade residual, utilizando como condiçâo inferior de contorno o atrito moderado (condição de escorregamento no fundo) e tem por base o balanço de forças mencionado acima, com exceção da tensão de cisalhamento do vento. A formulação de Miranda (1998) baseou-se no primeiro, mas diferenciou-se deste por considerar como condição inferior de contorno o atrito moderado, com o mesmo formalismo do modelo de Prandle (1985). As respectivas formulações utilizadas foram as seguinte:s:

Fisher et al. (1972)

Com este modelo foram calculados os perfis do componente longitudinal da velocidade $[u=u(x, Z)]$ e da salinidade $[S(x, Z)]$, em função da profundidade adimensional $(Z)$, tendo por condição inferior de contorno o atrito máximo $[u(x, 1)=0]$;

$$
\begin{aligned}
& u(x, Z)=\frac{g h^{3}}{N_{Z}} \frac{1}{\rho_{0}} \frac{\partial \bar{\rho}}{\partial x}\left(0,167 Z^{3}-0,188 Z^{2}+0,0208\right) \\
& +u_{f}\left(-1,5 Z^{2}+1,5\right)+\frac{\tau_{w x} h}{\rho_{0} N_{Z}}\left(0,75 Z^{2}-Z+0,25\right),
\end{aligned}
$$

$$
\begin{aligned}
& S(x, Z)=\langle\bar{s}\rangle+\left(\frac{h^{2}}{K_{z}} \frac{\partial\langle\bar{s}\rangle}{\partial x}\right) u(x, 0)\left(0,4 Z^{j}-0,75 Z^{4}+0,5 Z^{2}-0,08.3\right) \\
& \left.+u_{f}\left(-0,6 Z^{5}+Z^{4}-0,1\right)\right] .
\end{aligned}
$$

\section{Miranda (1998)}

Tal como o modelo anterior, foram calculados os perfis teóricos do componente longitudinal da velocidade e da salinidade, mas considerando como condição inferior de contono o atrito moderado $[u(x, 1) \neq 0]$ :

$$
\begin{aligned}
& u(x, Z)=\frac{g h^{2}}{k U_{o}} \frac{1}{\rho_{o}} \frac{\partial \bar{\rho}}{\partial x}\left(0,167 Z^{3}-0,296 Z^{2}+0,058\right) \\
& +u_{f}\left(1,106 Z^{2}+0,63\right)+\frac{\tau_{w x}}{\rho_{0} k U_{0}}\left(0,316 Z^{2}-Z+0,395\right),
\end{aligned}
$$




$$
\begin{aligned}
& S(x, Z)=\langle s\rangle+\left(\frac{h^{2}}{K_{Z}} \frac{\partial\langle\hat{s}\rangle}{\partial x}\right) u(x, 0)\left[\left(0,144 Z^{5}-0,425 Z^{+}+0,5 Z^{2}-0,105\right)\right] \\
& \left.+u_{f}\left(-0,092 Z^{5}+0,36 Z^{+}-0,057\right)\right] .
\end{aligned}
$$

As variáveis físicas desses modelos têm os seguintes significados: $g$ é a aceleração da gravidade, $h$ é a profundidade média local, $\mathrm{N}_{\mathrm{z}}$ é o coeficiente cinemático de viscosidade turbulento, $\rho_{v}$ é a densidade de referência $\left(10^{3} \mathrm{~kg} \mathrm{~m}^{-3}\right), \partial \bar{\rho} / \partial \mathrm{x}$ é o gradiente longitudinal médio de densidade, $\mathrm{u}_{\mathrm{f}}$ é a velocidade gerada pela descarga fluvial (considerada aproximadamente igual à velocidade residual durante um ciclo de maré), $\tau_{\text {rtr }}$ é a tensão de cisalhamento do vento simulada teoricamente, $<\bar{s}>$ é a média espaçotemporal da salinidade, $\partial<\bar{S}>/ \partial x$ é o correspondente gradiente longitudinal, $K_{2}$ é o coeficiente cinemático de difusão turbulento de sal e $u(x, 0)$ é a velocidade residual na superfície.

$\mathrm{Na}$ dedução dos perfis verticais das equações (3) e (4) foi utilizada, de acordo com Prandle (1985), para o coeficiente cinemático de viscosidade turbulento a expressão $N_{z}=k U_{0} h$, onde k é um coeficiente adimensional de atrito com o fundo e $\mathrm{U}_{0}$ é a amplitude da velocidade barotrópica.

\section{Prandle (1985)}

O modelo de Prandle (1985) calcula apenas o perfil do componente longitudinal da velocidade, considerando como condição de contorno inferior o atrito moderado $[u(x, 1) \neq 0]$, e assume desprezível a tensão de cisalhamento do vento. $\mathrm{Na}$ condição de estuários altamente estratificados, os perfis residuais nas camadas acima e abaixo da haloclina podem ser obtidos com as seguintes equações:

$$
u_{T}(Z)=-1,56 \frac{Q}{h} \frac{1}{(1-d)^{3}}\left\{\frac{Z^{2}}{2}-Z-0,808 d^{2}+1,616 d-0,308\right\}
$$

e

$u_{B}(Z)=-1,56 \frac{Q}{h} \frac{1}{d^{2}(1-d)}\left\{-0,574 Z^{2}+0,149 Z d+0,117 d^{2}\right\}$

em que $u_{T}$ e $u_{B}$ denotam as velocidades nas camadas superior e inferior, respectivamente, $Q$ é a descarga fluvial por unidade de largura $\left(\mathrm{m}^{2} \mathrm{~s}^{-1}\right), h$ tem o mesmo significado das equações anteriores, $D$ é a profundidade da interface entre as camadas e $d$ é a razão $\mathrm{D} / \mathrm{h}$. Neste caso, por tratar-se de um modelo aplicado para condições parcialmente misturadas, com a interface em torno da profundidade média da haloclina, os valores adotados para $d$ variaram entre 0,4 e 0,6 .
Como esses modelos analíticos assumem condições estacionárias, os resultados teóricos foram comparados a valores médios da salinidade e do componente longitudinal da velocidade, calculados no intervalo de tempo de pelo menos um ciclo completo de maré.

Os coeficientes cinemáticos de viscosidade turbulenta $\left(\mathrm{N}_{\mathrm{z}}\right)$ e de difusão turbulenta de sal $\left(\mathrm{K}_{\mathrm{z}}\right)$ foram alterados até que se conseguisse a melhor semelhança entre o resultado experimental e o teórico. Como cada perfil experimental foi simulado por três soluções diferentes no caso de $u$ (equações 1 , 3 e $5 a, b)$ e no caso de $S$ por duas (equações 2 e 4), os diferentes ajustes para uma mesma propriedade foram superpostos. Para que se obtivesse uma estimativa quantitativa entre os perfis experimental e teórico, também foram calculadas as correlações entre os resultados obtidos, com nível de significância de 0,95 . Em casos em que esse nível foi inferior a 0,6 as correlações foram rejeitadas estatisticamente. Como as soluções dos perfis verticais da salinidade dependem simultaneamente dos coeficientes $\mathrm{N}_{z}$ e $\mathrm{K}_{z}$, o ajuste de resultados teóricos aos experimentais foi mais difícil do que para a velocidade.

A região amostrada do Sistema Estuarinolagunar de Cananéia-Iguape foi a porção sul (Fig. lb), especificamente em três posições: i) próximo à Barra de Cananéia; ii) no Mar de Cananéia (imediações da Base de Pesquisas "Dr. João de Paiva Carvalho" do Instituto Oceanográfico) e iii) na Baía do Trapandé. Essas posições são referidas como estações Barra, Base e Trapandé, respectivamente. Os dados experimentais utilizados referem-se a Bonetti Filho (1995), Miranda et al. (1995) e Bérgamo (2000).

O levantamento ao longo do Canal de Bertioga ocorreu em cinco posições: na Barra de Bertioga, desembocadura do rio Itapanhaú, próximo à Marina Guarujá, na margem sul do manguezal do Largo do Candinho e na Base Aérea de Santos (Fig. 1c), às quais são referidas como estações Barra, Itapanhaú, Marina, Mangue e Base Aérea, respectivamente. Os dados de campo utilizados para calibração dos modelos provêm de Miranda \& Castro (1991), com observações horárias durante dois ciclos completos de maré $(25 \mathrm{~h})$ na estação Itapanhaú, além dos experimentos de Eichler (2001) nas demais estações, onde foram realizadas medidas horárias durante um ciclo completo de maré $(13 \mathrm{~h})$.

Os dois sistemas estuarinos em estudo apresentam características geométricas e estratificação de salinidade adequadas às hipóteses dos modelos analíticos:

i) canais relativamente estreitos: o que faz com que possam ser considerados lateralmente homogêneos e, portanto, uni ou bidimensionais de acordo com a estratificação vertical de salinidade (densidade)*,

$\overline{\left({ }^{*}\right)}$ A densidade, na maioria dos estuários de planície costeira, é funçâo apenas da salinidade. 
além de seções longitudinal e transversal que podem ser aproximadas por geometria simples e os efeitos topográficos são considerados desprezíveis;

ii) suas dimensões restritas atenuam a influência direta de ventos na geração de ondas de gravidade de substancial importância, além de inviabilizar o efeito dinâmico da rotação terrestre (a aceleração de Coriolis pode ser desprezada do componente longitudinal da equação do movimento).

\section{Resultados e discussão}

\section{Região sul do sistema estuarino-lagunar de Cananéia-Iguape}

Para ilustrar as simulações teóricas de condições experimentais do componente longitudinal de velocidade $(u)$ e da salinidade (S) são analisados os resultados de alguns experimentos. A Figura 2 apresenta, para a estação Base, os perfis médios (experimentais e teóricos) e os correspondentes desvios padrão durante o ciclo de maré.

Os dados experimentais foram obtidos em fevereiro de 1994 (antes do rompimento completo da barragem do Valo Grande), sob fase lunar de quadratura e mostram uma grande homogeneidade do perfil vertical médio no entorno de $\mathrm{S} \cong 28$ (Fig. 2a) e variabilidade horária dos dados experimentais de poucas unidades $(25,5-31,0)$ durante o ciclo de maré, indicando tratar-se de região com fraca estratificação vertical. $O$ componente $u$ apresentou grande variabilidade nesse período, principalmente na camada acima da haloclina (Fig. 2b), e as correntes de vazante foram mais intensas do que as de enchente; os valores extremos de vazante e enchente foram $-0,7$ $\mathrm{m} \mathrm{s}^{-1}$ e $0,4 \mathrm{~m} \mathrm{~s}^{-1}$, respectivamente.

Nessa simulação considerou-se, para todos os modelos, a descarga fluvial $\left(Q_{f}\right)$ igual a $95 \mathrm{~m}^{3} \mathrm{~s}^{-1} \mathrm{e}$ a seguinte geometria simplificada da seção transversal: profundidade e largura iguais a $6,9 \mathrm{~m}$ e $1.000 \mathrm{~m}$, respectivamente; logo, para o modelo de Prandle (1985), $Q=9,5 \times 10^{-2} \mathrm{~m}^{2} \mathrm{~s}^{-1}$. No cálculo do gradiente longitudinal de densidade dos modelos de Fisher et al. (1972) e Miranda (1998), considerou-se $\Delta \mathrm{x}=3.200 \mathrm{~m}$, resultando para esse gradiente o valor $1,22 \times 10^{-3} \mathrm{~kg} \mathrm{~m}^{-4}$. Para o primeiro modelo o melhor ajuste do perfil da velocidade residual foi obtido com $\mathrm{N}_{\mathrm{z}}=2,53 \times 10^{-3} \mathrm{~m}^{2} \mathrm{~s}^{-1}$ e para o segundo com os seguintes parâmetros: $\mathrm{U}_{0}=1,22 \mathrm{~m} \mathrm{~s}^{-1}$ e $\mathrm{k}=3,0 \times 10^{-4}$. Para simular os perfis verticais de salinidade, o coeficiente cinemático de difusão turbulenta de sal mais conveniente foi $\mathrm{K}_{\mathrm{z}}=2,0 \times 10^{-6} \mathrm{~m}^{2} \mathrm{~s}^{-1}$. Dentre as simulações com os dois primeiros modelos, o valor $\mathrm{da}$ tensão de cisalhamento do vento que melhor se ajustou às condições experimentais foi $\tau_{w x}=0$.

$\mathrm{Na}$ Figura 2 observa-se que todos os modelos reproduziram com sucesso as condições experimentais médias. Em relação à salinidade (Fig. 2a), o desvio entre os dados experimentais $\mathrm{e}$ as simulações foi maior nas proximidades do fundo, mas a haloclina na camada intermediária foi bem simulada. A velocidade residual foi caracterizada por uma distribuição vertical quase uniforme do componente $u$ (Fig. 2b), com movimentos unidirecionais para a desembocadura do sistema, o que também foi simulado pelos modelos. Tais características indicam condições típicas de estuários fracamente estratificados forçados predominantemente pela maré.
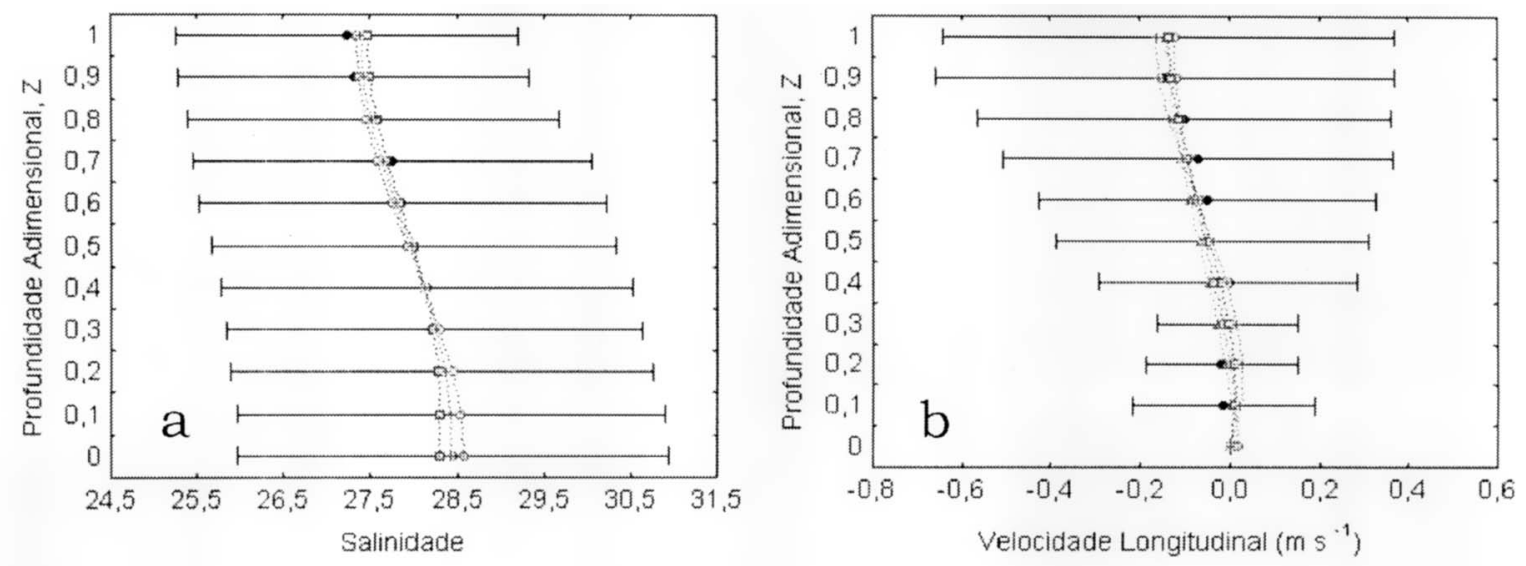

Fig. 2. Ajustes dos perfis teóricos de salinidade (a) e do componente longitudinal da velocidade (b) às condições experimentais (•) na estação Base antes do rompimento da barragem do Valo Grande, com os modelos de Prandle (1985) ( $\Delta$ ) e Miranda (1998) (o), com escorregamento no fundo, além de Fisher et al. (1972) ( $\square$ ) sem escorregamento de fundo. Os segmentos horizontais representam os desvios padrão dos dados experimentais. 
Com a ruptura da barragem do Valo Grande, ocorreu a intensificação da descarga de água doce em torno de uma ordem de grandeza na região em estudo (Bérgamo, 2000). Uma das conseqüências desse processo pode ser evidenciada nos perfis verticais de $\mathrm{S}$ e $u$ (Fig. 3), em experimento também realizado na maré de quadratura, em fevereiro de 1998. Na Figura 3a observa-se a presença da haloclina (16-20), com maior gradiente vertical de salinidade, e a maior variabilidade dessa propriedade, principalmente nas camadas mais próximas ao fundo devido à influência marinha. $\mathrm{O}$ valor médio da salinidade foi menor do que no experimento anterior.

Com o aumento na descarga fluvial, associado a um menor efeito difusivo da maré (fase de quadratura), a distribuição vertical de $u$ (Fig. 3b) também foi alterada em relação à anterior: maior variabilidade horária ao longo do ciclo de maré, atingindo valores de até $-1,1$ e 0,5 $\mathrm{m} \mathrm{s}^{-1}$ na vazante e enchente, respectivamente.

Em relação ao experimento anterior, os parâmetros que foram alterados para os ajustes teóricos, com base nas condições do experimento, foram os seguintes: a profundidade passou para $8,6 \mathrm{~m}$ e o gradiente longitudinal de densidade que foi reduzido para $0,572 \times 10^{-3} \mathrm{~kg} \mathrm{~m}^{-4}$. Para o modelo de Fisher et al. (1972) o melhor ajuste do perfil da velocidade residual foi obtido com um valor menor $\mathrm{N}_{\mathrm{z}}=0,85 \times 10^{-3} \mathrm{~m}^{2} \mathrm{~s}^{-1}$ e para o de Miranda (1998) as melhores simulações foram com os seguintes parâmetros: $\mathrm{k}=5,95 \times 10^{-5}$ e $\mathrm{U}_{0}=1,095$ $\mathrm{m} \mathrm{s}^{-1}$. Para simular os perfis verticais de salinidade, o coeficiente cinemático de difusão turbulenta de sal utilizado foi $\mathrm{K}_{\mathrm{z}}=0,6 \times 10^{-6} \mathrm{~m}^{2} \mathrm{~s}^{-1}$. Tal como no caso anterior, dentre as simulações realizadas, o valor da tensão de cisalhamento do vento que melhor se ajustou às condições experimentais foi quando tal efeito foi considerado nulo $\left(\tau_{\mathrm{wx}}=0\right)$.

Nesse experimento, tem-se uma situação típica de estuários parcialmente misturados. Tal como no primeiro, o maior desvio entre os resultados teóricos e experimentais observado no perfil vertical de salinidade (Fig. 3a) foi nas proximidades do fundo. Em relação ao perfil vertical da velocidade residual (Fig. 3b) a condição é típica de estuário parcialmente misturado, cujos movimentos bidirecionais (circulação gravitacional) foram simulados adequadamente pelos modelos analíticos.

Os resultados experimentais das três estações fixas amostradas nessa região (Fig. 1b), antes e depois do rompimento da barragem do Valo Grande, bem como as simulações teóricas de perfis verticais de $u$ e $\mathrm{S}$, encontram-se descritos detalhadamente em Bernardes (2001). Nesse trabalho observam-se mudanças significativas nessas propriedades: a região deixou de apresentar características de um sistema bem misturado e unidirecional, alternando-se entre bem misturado e parcialmente misturado, de acordo com a intensidade da descarga fluvial e a altura da maré.
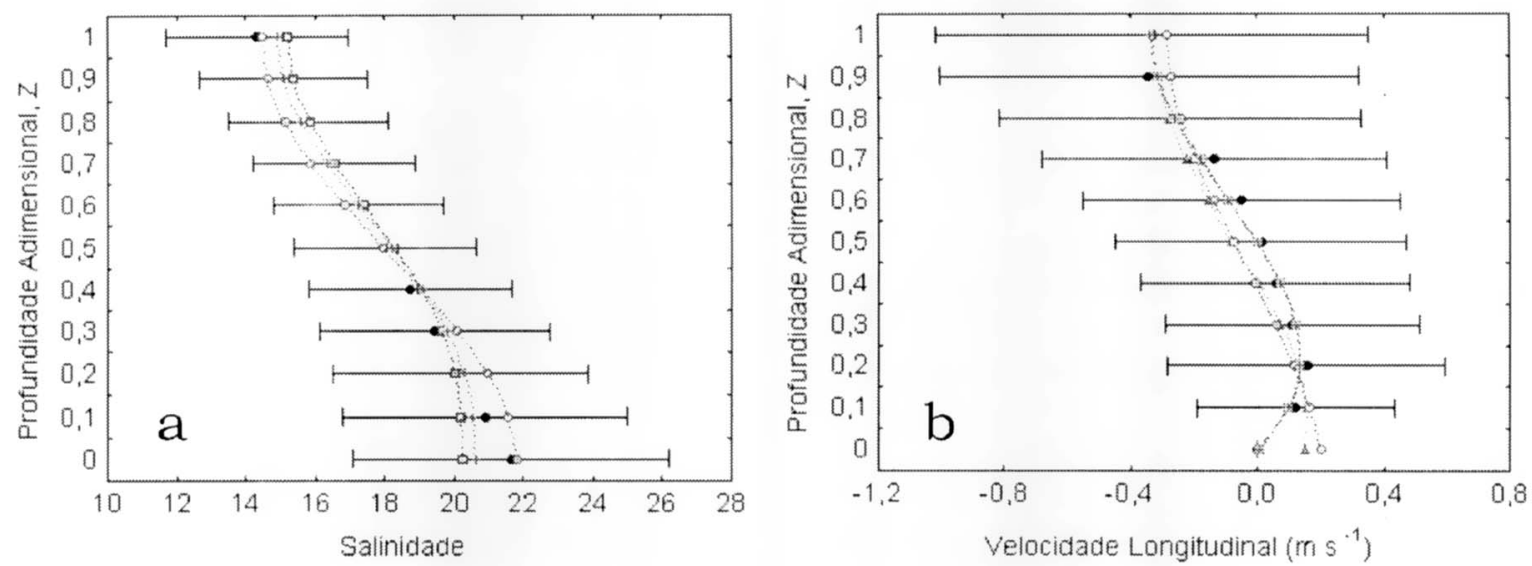

Fig. 3. Ajustes dos perfis teóricos de salinidade (a) e do componente longitudinal da velocidade (b) às condições experimentais (•) na estação Base após o rompimento da barragem do Valo Grande, com os modelos de Prandle (1985) ( $\mathbf{\Delta}$ ) e Miranda (1998) (o), com escorregamento no fundo, além de Fisher et al. (1972) ( ) sem escorregamento de fundo. Os segmentos horizontais representam os desvios padrão. 
A análise dos perfis médios experimentais de $\mathrm{S}$ nessas estações demonstra o surgimento de uma haloclina após o rompimento da barragem do Valo Grande (Fig. 4a), indicando a maior influência de águas de origem continental. Em média, as estações Base $(\bullet, \boldsymbol{\bullet})$ e Baía do Trapandé $(\boldsymbol{\Delta})$ foram as que apresentaram a maior influência da descarga fluvial, evidenciada pelos menores valores de salinidade média em superfície.

Apesar da descarga fluvial da bacia do rio Ribeira de Iguape ocorrer preferencialmente pelo Mar de Cananéia (onde se localiza a estação Base), a estação Baía do Trapandé recebe aporte direto de água doce proveniente da bacia de drenagem local que, apesar de uma vazão bem inferior à da bacia do Ribeira, desemboca próximo à estação em questão. Na estação Barra (+) observou-se, devido aos valores médios das salinidades mais elevados, a maior influência de águas marinhas. Em todas as situações foram observadas características de circulação gravitacional (Fig. 4b), sendo o perfil referente à situação antes do rompimento do Valo Grande o menos intenso. As estações Base (-) e Barra $(+)$ foram as que apresentaram as maiores intensidades do componente longitudinal de velocidade.
O ajuste dos modelos analíticos às condições experimentais identificou o gradiente longitudinal de densidade e a descarga de água doce, como principais forçantes da circulação estacionária no Sistema Estuarino-lagunar de Cananéia, em detrimento da influência secundária do vento local. Esse padrão também foi observado por Miranda (1990) e Miranda \& Castro (1996). Entretanto, devido às dificuldades de medidas representativas do vento local nesse sistema estuarino, faz necessária uma análise mais detalhada sobre a influência dessa forçante sobre a circulação e processos de mistura.

As soluções teóricas dos modelos analíticos conseguiram, na grande maioria dos casos analisados, reproduzir com correlações elevadas as principais características hidrodinâmicas observadas experimentalmente. A Figura 5 mostra que todos os experimentos apresentaram uma correlação média, para $u$ e S, superior a 0,6 . Para a salinidade (Fig. 5a) apenas em um experimento a solução teórica não foi satisfatória enquanto que para o componente $u$ (Fig. $5 b)$, três experimentos tiveram uma de suas correlações rejeitada estatisticamente. Esses resultados confirmam que o comportamento quaseestacionário do sistema foi adequadamente descrito pela formulação teórica.
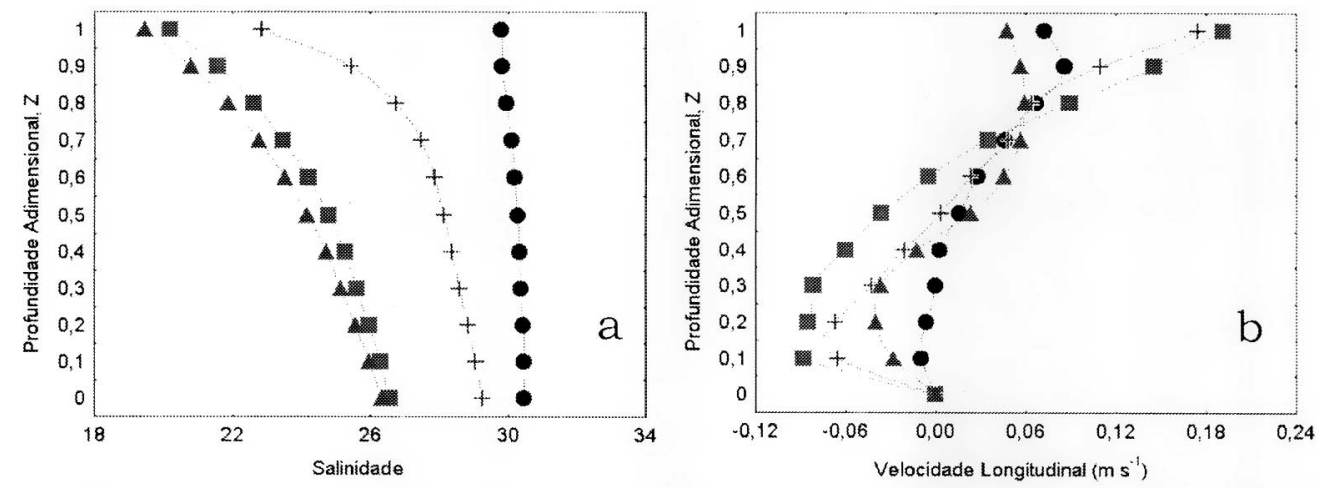

Fig. 4. Perfis médios experimentais de salinidade e velocidade longitudinal $\left(\mathrm{m} \mathrm{s}^{-1}\right)$ para a região de Cananéia, com a seguinte legenda: estação Base antes $(\bullet)$ e após $(\bullet)$ o rompimento da barragem do Valo Grande; estações Barra (+) e Baía do Trapandé ( $\boldsymbol{\Delta}$ ), após o rompimento da barragem do Valo Grande.
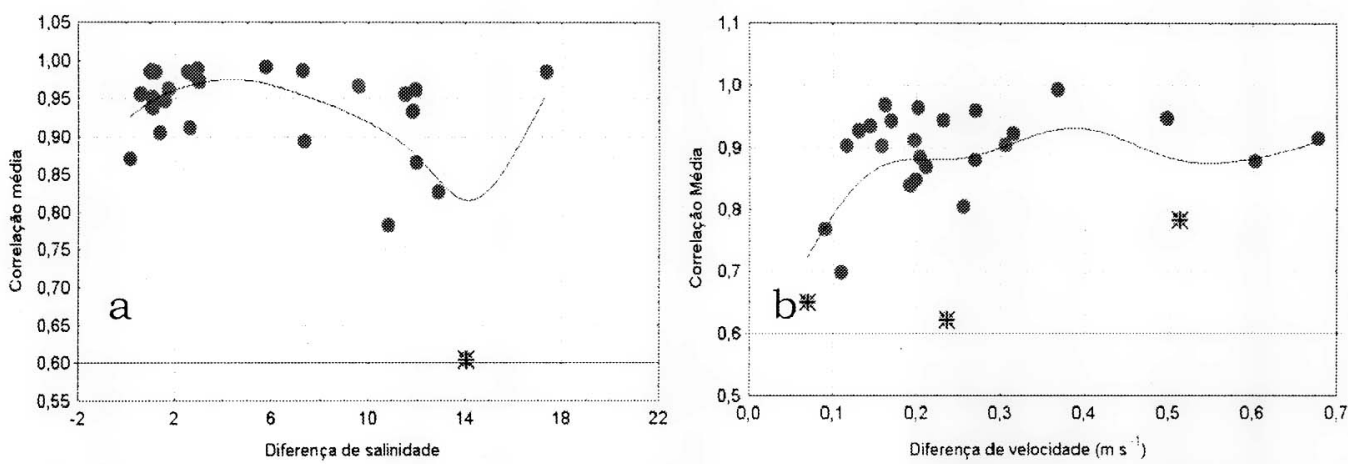

Fig. 5. Correlações médias entre as soluções teóricas e os perfís experimentais de salinidade (a) e da velocidade longitudinal (b) para Cananéia. Soluções cuja correlação não apresentou valores inferiores a 0,6 e quando apenas uma das soluções foi rejeitada, estão indicadas por $(\bullet)$ e $(*)$, respectivamente. 
As soluções teóricas que contemplaram a condição de contorno com escorregamento no fundo foram as que, em linhas gerais, apresentaram as menores correlações. Entretanto, não se pode afirmar que essa condição não é adequada para o canal estuarino em estudo pois, devido ao tipo de equipamento utilizado nas medidas de corrente, não foi possivel amostrar a camada limite de fundo. Além do mais, no tratamento dos dados experimentais, assumimos por hipótese a condição de atrito máximo no fundo $(u=0)$.

A variação dos coeficientes de viscosidade turbulenta $\left(\mathrm{N}_{\mathrm{z}}\right)$ nas estações pesquisadas, gerados pelas soluções de Prandle (1985) e de Fisher et al. (1972), indicam que a estação Barra é a que apresenta maiores valores médios e maior variabilidade (Figs. 6a,b). Como citado anteriormente, o fato de as maiores profundidades de amostragem estarem na estação Barra contribui para que esta estação apresente os maiores valores para os coeficientes de viscosidade turbulenta, devido a dependência do atrito de fundo com a espessura da camada de água. Além disso, a proximidade da estação Barra à boca do estuário favorece condições hidrodinâmicas mais intensas, com maiores valores e maior variabilidade desse coeficiente.

Outra característica hidrodinâmica importante diz respeito à preponderância do efeito difusivo da maré, aumentando os coeficientes de viscosidade turbulenta. Sobretudo nas épocas de sizígia a mistura proporcionada pela maré superou a gerada por efeito da circulação gravitacional em quadratura, condição esta que normalmente favorece a estratificação da salinidade, dificultando o processo de mistura vertical. Tal modulação foi realçada nas estações Base e Barra após o rompimento da barragem do Valo Grande, enquanto na estação Baía do Trapandé não houve diferença significativa entre os experimentos de sizígia e quadratura.

Apenas o modelo de Prandle (1985) coloca a estação Base, após o rompimento da barragem do Valo Grande, com características parecidas com às da estação Barra, em relação à variabilidade do coeficiente cinemático de viscosidade turbulenta (Fig. 6). Esse resultado parece ser a resposta hidrodinâmica adequada, já que houve uma mudança considerável na circulação após o rompimento da barragem e os dados experimentais de ambas estações indicaram tal semelhança. As outras duas estações, Base antes do rompimento e Baía do Trapandé, apresentaram valores médios baixos desse coeficiente e também pequena variabilidade.

De modo geral, os coeficientes cinemáticos de difusão turbulenta $\left(\mathrm{K}_{\mathrm{z}}\right)$ apresentaram ordens de grandeza semelhantes e os resultados dos ajustes teoria-experimentação indicam que as simulações com modelo de Fisher et al. (1972) correspondem ao comportamento desse coeficiente (Fig. 7). A partir da comparação entre os resultados teóricos gerados pelos modelos e a estimativa experimental realizada por Mesquita et al. (1992) para o mesmo conjunto de dados, pode-se dizer que os resultados teóricos foram bastante satisfatórios.
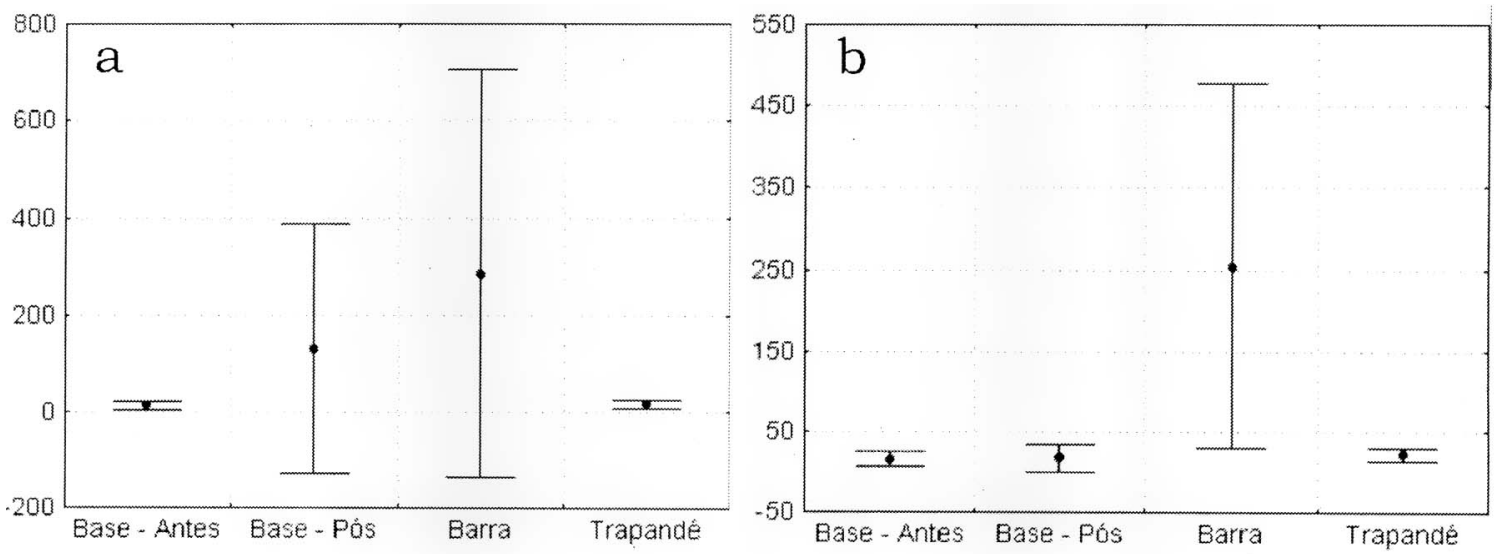

Fig. 6. Médias e desvios padrão dos coeficientes cinemáticos de viscosidade turbulenta $\mathrm{N}_{\mathrm{z}}$, em unidades de $10^{-4} \mathrm{~m}^{2}$ $\mathrm{s}^{-1}$, estimados para as estações de Cananéia com os modelos de Prandle (1985) e Fisher et al. (1972), cujos resultados são indicados por $a$ e $b$, respectivamente. 


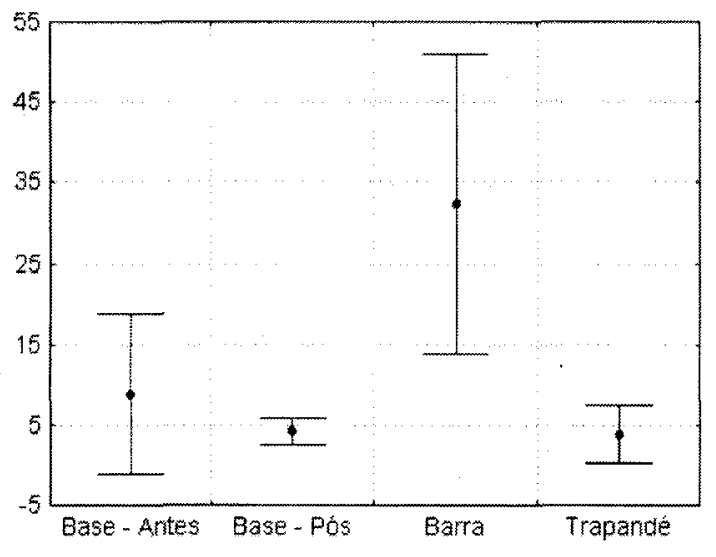

Fig. 7. Médias e desvios padrão dos coeficientes cinemáticos de difusão turbulenta $\mathrm{K}_{\mathrm{z}}$, em unidades de $10^{-7} \mathrm{~m}^{2} \mathrm{~s}^{-1}$, estimados para as estações de Cananéia com o modelo de Fisher et al. (1972).

A estação Base mostrou uma forte dependência do efeito advectivo da descarga fluvial, como se observa dos resultados antes e depois do rompimento da barragem do Valo Grande e sua classificação, de acordo com o Diagrama Estratificação-circulação, variou do Tipo $2 \mathrm{a}$ para $2 \mathrm{~b}$ (Miranda \& Castro, 1998; Bérgamo, 2000). Portanto, na condição anterior ao rompimento, os processos difusivos dominavam o transporte de sal estuário acima e a descarga fluvial teve sua magnitude comparável à da maré apenas nos meses de maior precipitação pluviométrica.

A intensificação da circulação gravitacional, observada após o rompimento da barragem do Valo
Grande, indicou a maior influência do efeito advectivo da descarga fluvial na redistribuição longitudinal de sal, gerando valores mais intensos do componente baroclínico da força de gradiente de pressão. Os coeficientes de difusão turbulenta mais altos e variáveis na estação Barra (Fig. 7) podem ser explicados pelas correntes mais intensas, maior profundidade e a complexa topografia do fundo submarino.

\section{O Canal de Bertioga}

Os experimentos nas estações Base Aérea e Barra, localizadas nos extremos oeste e leste do canal (Fig. 1c), respectivamente, foram escolhidos para ilustrar a simulação das condições experimentais com os modelos analíticos. Esses experimentos foram realizados no verão (janeiro de 2000 ) em condições de maré de quadratura.

O perfil de salinidade médio na estação Base Aérea (Fig. 8a) mostra considerável estratificação vertical, aumentando de 12 na superfície a 29 no fundo, e o gradiente vertical de salinidade na haloclina é relativamente intenso. A variabilidade horária da salinidade é alta na camada da haloclina, decrescendo gradativamente em direção à superfície $\mathrm{e}$ ao fundo. A variação do componente u da velocidade no entorno da média foi bastante acentuada, mas com menor intensidade do que em Cananéia, com extremos de $-0,12$ a $+0,12 \mathrm{~m} \mathrm{~s}^{-1}$ nas condições de vazante e enchente (Fig. 8b). Em conseqüência, o componente longitudinal da velocidade residual variou aproximadamente entre $-0,02$ e $0,01 \mathrm{~m} \mathrm{~s}^{-1}$.
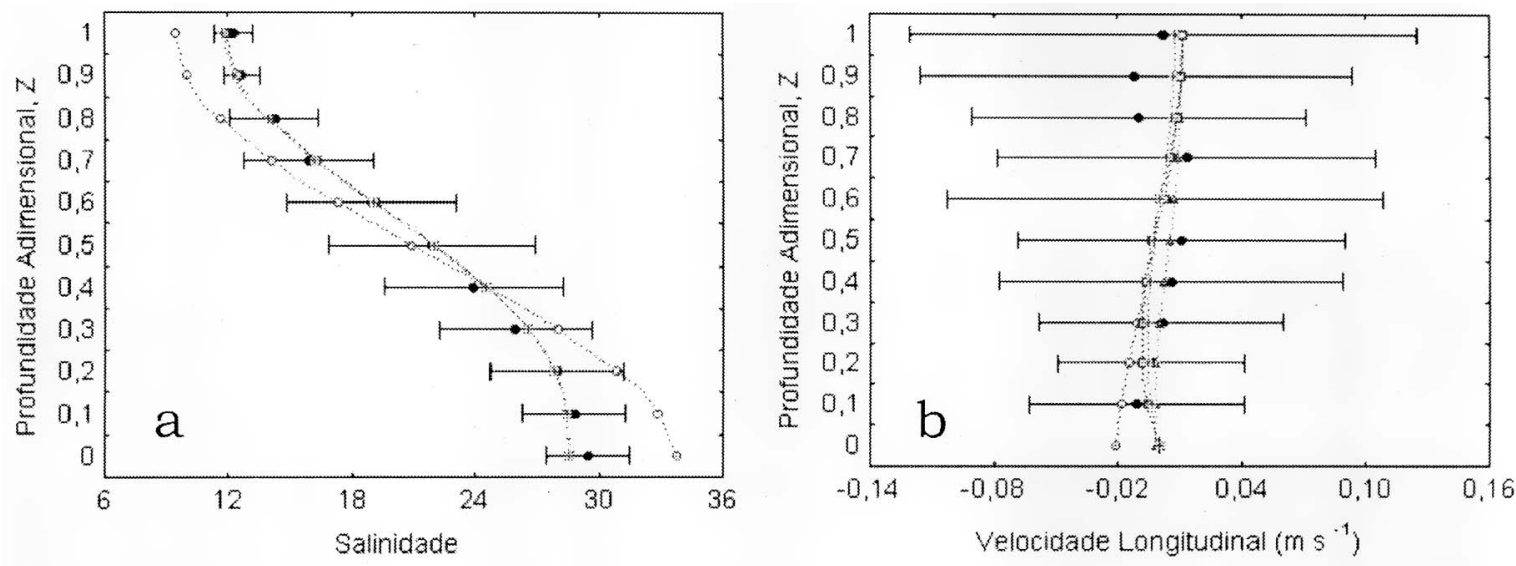

Fig. 8. Ajustes dos perfis teóricos de salinidade (a) e do componente longitudinal da velocidade (b) às condições experimentais na estação Base Aérea (•), com os modelos de Prandle (1985) ( $\Delta$ ) e Miranda (1998) (o), com escorregamento no fundo, além de Fisher et al. (1972) ( $\square$ ) sem escorregamento de fundo. Os segmentos horizontais representam os desvios padrão dos dados experimentais. 
Considerando que nessa época do ano são atingidos os maiores valores da descarga fluvial, na aplicação dos modelos a descarga fluvial $\left(\mathrm{Q}_{\mathrm{f}}\right)$ adotada foi igual a $10 \mathrm{~m}^{3} \mathrm{~s}^{-1}$. Para os experimentos numéricos na estação Base Aérea além da secção transversal com geometria simples (profundidade e largura iguais a $5,3 \mathrm{~m}$ e $400 \mathrm{~m}$, respectivamente) foram ainda utilizados os seguintes parâmetros: $\Delta x=4.800 \mathrm{~m}$, resultando para o gradiente longitudinal de densidade o valor $0,394 \times 10^{-3} \mathrm{~kg} \mathrm{~m}^{-4}$; para os modelos de Fisher et al. (1972) e Miranda (1998) os melhores ajustes do perfil da velocidade residual foram obtidos com $\mathrm{N}_{\mathrm{z}}=2,32 \times 10^{-3} \mathrm{~m}^{2} \mathrm{~s}^{-1}, \mathrm{U}_{0}=1,46 \mathrm{~m} \mathrm{~s}^{-1}$ e $\mathrm{k}=0,3 \times 10^{-3}$. Entretanto, os ajustes do perfil da salinidade, com as equações (2) e (4), somente foram possíveis com valores de $\mathrm{K}_{\mathrm{z}}$ muito pequenos e da ordem de $0,3 \times 10^{-9}$ $\mathrm{m}^{2} \mathrm{~s}^{-1}$.

Para o modelo de Prandle (1985) a variável $Q$ é igual a $2,5 \times 10^{-2} \mathrm{~m}^{2} \mathrm{~s}^{-1}$, com as melhores simulações obtidas com $0,4<\mathrm{d}<0,6$. Dentre as simulações com os dois primeiros modelos, o valor da tensão de cisalhamento do vento que melhor se ajustou às condiçờes experimentais foi quando tal efeito foi considerado nulo $\left(\tau_{\mathrm{wx}}=0\right)$.

Os resultados das simulações do perfil vertical médio de salinidade na estação Base Aérea indicam que o modelo de Fisher et al. (1972) foi o mais adequado (Fig. 8a). Entretanto, provavelmente devido à pequena intensidade da corrente, o perfil vertical da velocidade residual não foi simulado adequadamente pelos modelos analíticos, principalmente na camada superficial (Fig. 8b).
No experimento realizado na estação Barra, localizada nas proximidades da maior fonte pontual de água doce do canal de Bertioga, o Rio Itapanhaú, observa-se no perfil médio de salinidáde (Fig. 9a) pronunciada haloclina em que $14<\mathrm{S}<32$, e sob essa camada condições quase homohalinas ( $\mathrm{S} \cong 33)$, indicando tratar-se de uma região altamente estratificada; a variabilidade no decorrer do ciclo de maré é relativamente grande na haloclina, decrescendo em direção às camadas mais profundas. $\mathrm{O}$ componente $\mathrm{u}$ apresentou grande variabilidade horária na camada da haloclina, com intensidades entre $0,40 \mathrm{e}-0,18 \mathrm{~m} \mathrm{~s}^{-1}$ nas condições de vazante e enchente, respectivamente (Fig. 9b). O perfil da velocidade residual indica a circulação clássica de estuários parcialmente misturados, com intensidades entre os extremos de 0,17 e $-0,05 \quad \mathrm{~m} \mathrm{~s}^{-1}$, respectivamente.

$\mathrm{Na}$ simulação dos perfis estacionários nesta estação a geometria simples adotada foi profundidade e largura iguais a $6,1 \mathrm{~m}$ e $400 \mathrm{~m}$, respectivamente. Para calcular o gradiente longitudinal de densidade dos modelos de Fisher et al. (1972) e Miranda (1998), considerou-se $\Delta x=10.300 \mathrm{~m}$, resultando para esse gradiente o valor $0,582 \times 10^{-3} \mathrm{~kg} \mathrm{~m}^{-4}$.

Para os modelos de Fisher et al. (1972) e Miranda (1998) os melhores ajustes do perfil da velocidade residual foram obtidos com $\mathrm{N}_{\mathrm{z}}=4,6 \times 10^{-4}$ $\mathrm{m}^{2} \mathrm{~s}^{-1}, \mathrm{k}=0,55 \times 10^{-4}$ e $\mathrm{U}_{0}=1,36 \mathrm{~m} \mathrm{~s}^{-1}$. Para simular os perfis de salinidade com as equações (2) e (4) foi utilizado um coeficiente $\mathrm{K}_{z}$ duas ordens de grandeza maior $\left(0,8 \times 10^{-7}\right)$ do que para a estação Base Aérea.
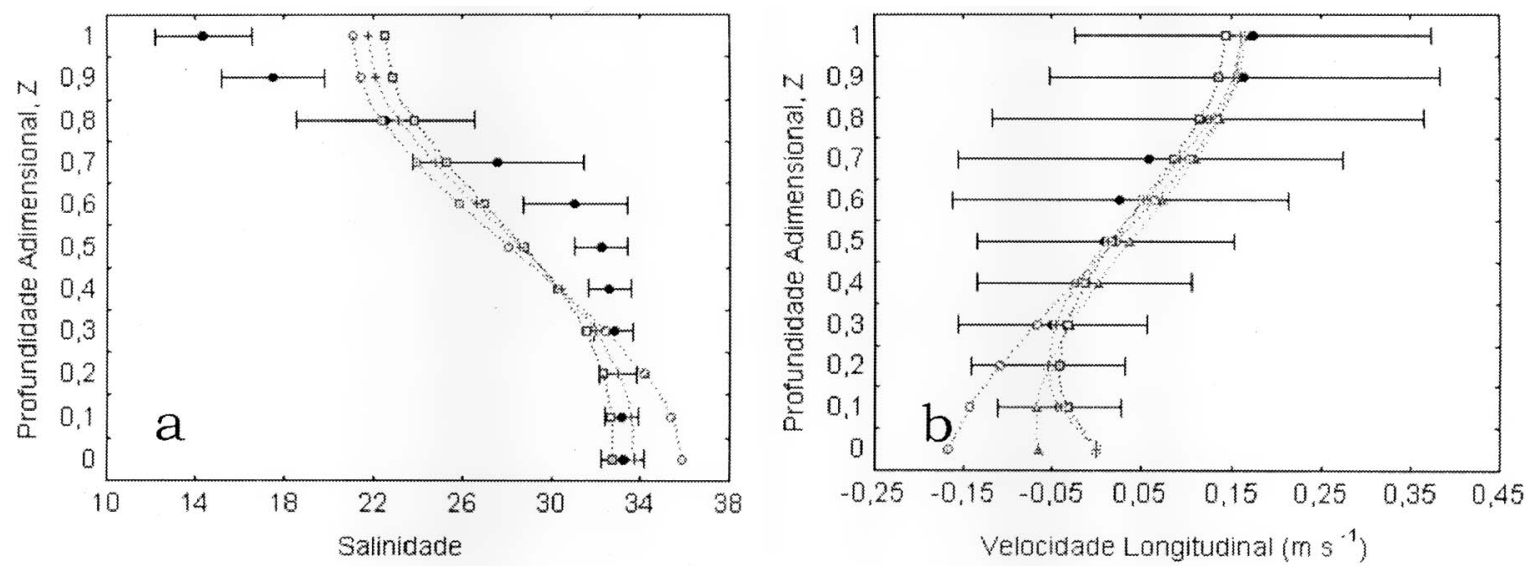

Fig. 9. Ajustes dos perfis teóricos de salinidade (a) e do componente longitudinal da velocidade (b) às condições experimentais na estação Barra $(\bullet)$, com os modelos de Prandle (1985) ( $\Delta$ ) e Miranda (1998) (o), com escorregamento no fundo, além de Fisher et al. (1972) ( $\square$ ) sem escorregamento de fundo. Os segmentos horizontais representam os desvios padrão dos dados experimentais. 
Os resultados das simulações dos perfis de salinidade apresentam um grande desvio entre os valores experimentais e os teóricos (Fig. 9a), principalmente na camada da haloclina, muito provavelmente pela proximidade da principal fonte de água doce (Rio Itapanhaú). Como essa característica da estrutura salina é típica de estuários do tipo altamente estratificado ou cunha salina, justificam-se os desvios entre as simulações $\mathrm{e}$ os dados experimentais. Entretanto, em relação ao perfil vertical do componente u (Fig. 9b), a circulação gravitacional foi bem simulada, embora com menor intensidade em relação à observada no experimento de Cananéia (estação Barra). Os modelos reproduziram bem as condições experimentais da velocidade residual, principalmente os que adotaram como condição inferior de contorno o atrito máximo no fundo.

Assim como para Cananéia, nesses experimentos teóricos o valor da tensão de cisalhamento do vento que melhor se ajustou às condições experimentais foi quando tal efeito foi considerado desprezível; vale lembrar que essa forçante não é considerada no modelo de Prandle (1985) e suas simulações também foram satisfatórias. Sendo assim, com a aplicação dos modelos analíticos observou-se que o gradiente longitudinal de densidade e a descarga fluvial também foram evidenciados como as principais forçantes da circulação estacionária no canal de Bertioga.

A 'comparação dos perfis médios experimentais de cada estação (Fig. 10) permitiu uma análise mais geral do comportamento hidrodinâmico do Canal de Bertioga. A salinidade em superfície (Fig.10a) variou pouco, entre 20,2 e 22,7. O principal diferencial entre as estações foi o valor da salinidade no fundo que em média variou de 25 a 31,5.

A estação Barra foi a que apresentou maior influência de águas da plataforma continental, identificada pela haloclina com acentuado gradiente vertical de salinidade (Fig. - 10a). Na estação Itapanhaú também foi observada variação considerável na estrutura vertical de salinidade. Os perfis médios da salinidade das estações Marina, Mangue e Base Aérea são bastante semelhantes, sendo que na estação Marina foi observada a menor salinidade média $(S \cong 20)$ em superfície, o que indica que essa estação sofreu maior influência da descarga fluvial. Por sua vez, a estação Mangue foi a que apresentou a menor estratificação vertical de $\mathrm{S}$, indício de que a penetração da cunha salina nessa região foi menos eficiente do que nos outros locais amostrados.

Os perfis verticais de $u$ (Fig. 10b) mostram, mais uma vez, uma semelhança maior entre as estações Barra e Itapanhaú e a afinidade entre as outras três. No primeiro grupo encontram-se perfis bidirecionais característicos de sistemas parcialmente misturados, com as camadas superiores se dirigindo à Barra de Bertioga, e as inferiores em direção ao interior do canal. Destaque para a maior intensidade do perfil da estação Itapanhaú que, mesmo sob condições de baixa descarga fluvial, reforçou o padrão de alta estratificação nesse ponto do canal.

Ao contrário da circulação gravitacional do grupo anterior (estações Barra e Itapanhaú), neste estão classificadas as estações cujas velocidades foram pouco intensas e com fluxos de tendência unidirecional (Fig. 10b). A partir dos dados experimentais, a estação Marina não apresentou um sentido preferencial de propagação, enquanto na estação Mangue prevaleceu o sentido em direção ao Largo do Candinho e na estação Base Aérea o fluxo dirigiu-se para o Canal de Piaçaguera. Entretanto, como as velocidades desse grupo são baixas e próximas ao valor mínimo de medida do sensor de velocidade utilizado, esses resultados devem ser analisados com cautela.
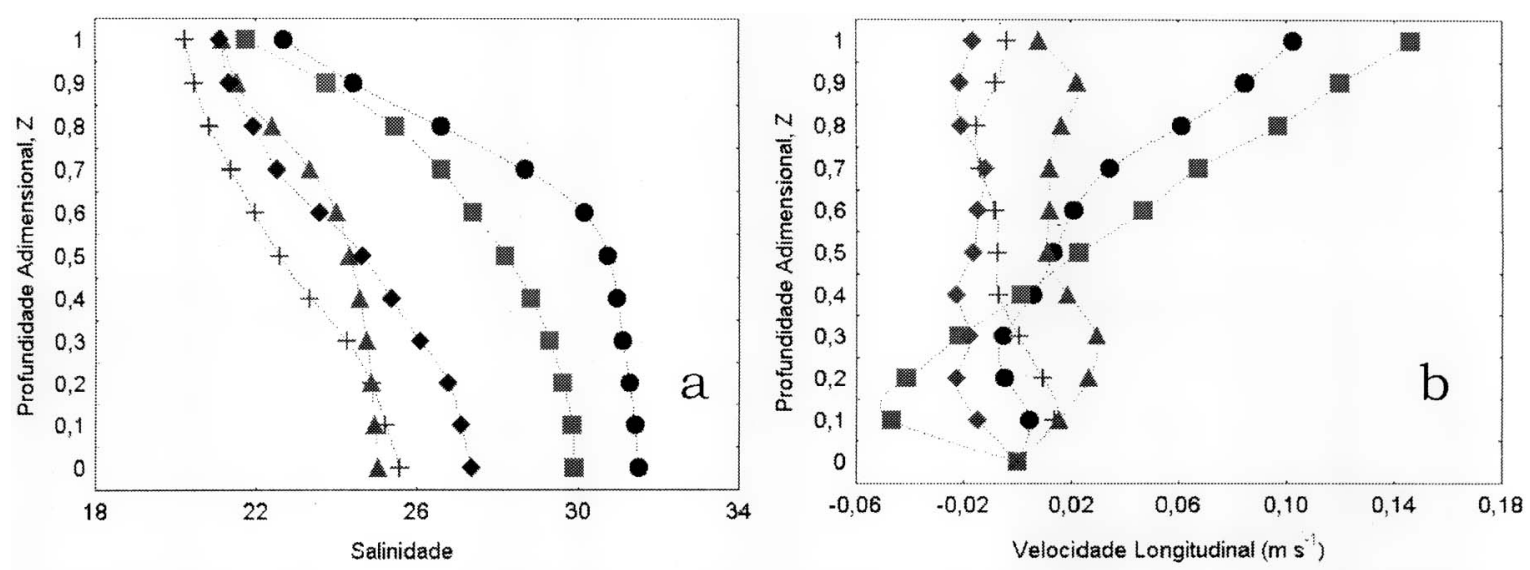

Fig. 10. Perfis médios experimentais de salinidade e velocidade longitudinal $\left(\mathrm{m} \mathrm{s}^{-1}\right)$ ao longo do Canal de Bertioga, com a seguinte legenda: estações Barra $(\bullet)$, Itapanhaú (•), Marina (+), Mangue $(\boldsymbol{\Delta})$ e Base Aérea $(\bullet)$. 
Apesar dos perfis médios de $u$ (Fig. 8b) na estação Base Aérea indicarem condições de baixa energia, os desvios padrão no entorno da média sugerem tratar-se de região com acentuada competência para o transporte de sedimentos. Essa característica está de acordo com Eichler (2001), cujos resultados da coleta de sedimentos realizadas nas mesmas datas desses experimentos, indicam a presença de material mais arenoso nas imediações dessa estação.

O Diagrama Estratificação-circulação foi utilizado na classificação do canal estuarino. $O$ comportamento observado reforça a idéia de que existe uma compartimentação entre a região do canal próxima à desembocadura do Rio Itapanhaú (estações Barra e Itapanhaú) e as porções mais interiores do canal, já que os baixos valores dos parâmetros estratificação e circulação das estações Marina, Mangue e Base Aérea indicam condições hidrodinâmicas pouco intensas e fracamente estratificadas (estuário Tipo 1a). Essa diferenciação foi analisada por Miranda et al. (1998), que identificaram condições de significativa estratificação de $\mathrm{S}$ nas proximidades da desembocadura do rio Itapanhaú e uma progressiva mistura vertical em direção ao Largo do Candinho. Esses autores também sugeriram que o estreitamento no canal a oeste do Largo do Candinho minimizaria a troca de água e de sal entre o Canal de Bertioga e o complexo estuarino de Santos. Fúlfaro \& Ponçano (1976) também corroboram com essa hipótese na medida em que caracterizaram o transporte sedimentar no canal como predominantemente por suspensão, típico de ambientes de baixa hidrodinâmica.
As estações Marina e Base Aérea foram classificadas como bem misturadas (Tipo 1b). Por sua vez, as estações Barra e Itapanhaú, localizadas a cerca de $4 \mathrm{~km}$ da boca do canal estuarino, foram classificadas como parcialmente misturadas (Tipo 2a) na fase de sizígia, com predomínio da difusão turbulenta $(\cong 90 \%)$ no transporte de sal estuário acima, enquanto apenas $10 \%$ foi relacionado ao transporte advectivo. Esse resultado reforça a hipótese de Miranda et al. (1998), que propõem que a difusão turbulenta seja o principal mecanismo de mistura nessa fase de maré.

As correlações entre as soluções teóricas e os perfis experimentais de salinidade no Canal de Bertioga (Fig. 11a) foram muito boas. Entretanto, os perfis experimentais de $u$ foram apenas razoavelmente bem representados pelas soluções teóricas (Fig. 11b). Os três experimentos que tiveram suas correlações rejeitadas estatisticamente apresentavam diferenças entre os extremos de velocidade inferiores a $0,06 \mathrm{~m} \mathrm{~s}^{-1}$. Os experimentos que tiveram apenas uma de suas correlações rejeitadas tiveram diferenças de velocidade entre $0,02 \mathrm{~m} \mathrm{~s}^{-1}$ e $0,06 \mathrm{~m} \mathrm{~s}^{-1}$ e aquelas em que todas as correlações foram estatisticamente significativas e superiores a $80 \%$ ficaram com diferenças maiores do que $0,07 \mathrm{~m} \mathrm{~s}^{-1}$. Entretanto, as soluções teóricas rejeitadas ocorreram em experimentos com velocidades residuais muito baixas (em módulo $<0,02 \mathrm{~m} \mathrm{~s}^{-1}$ ), geralmente próximas à precisão do sensor de velocidade, características de locais dominados pela maré (Tipo 1).
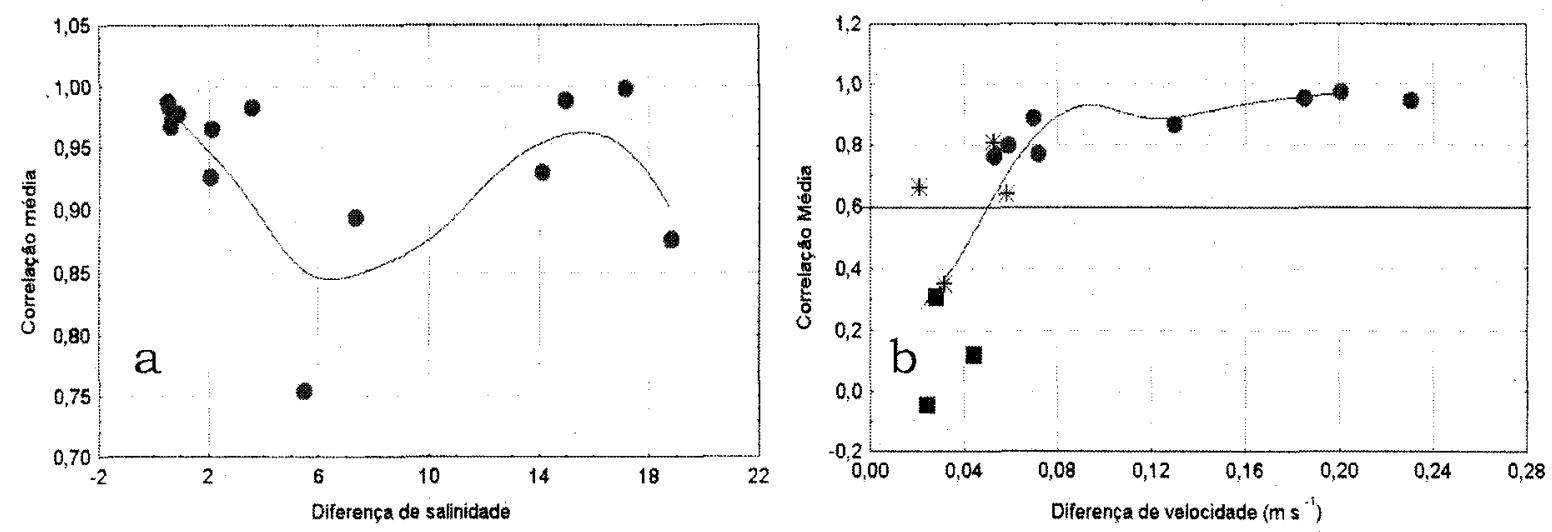

Fig. 11. Correlações médias entre as soluções teóricas e os perfis experimentais de salinidade e de velocidade longitudinal para o Canal de Bertioga. Soluções cuja correlação não apresentou valores inferiores a 0,6 e quando apenas uma das soluções foi rejeitada, estão indicadas por $(\bullet)$ e (*), respectivamente. $\mathrm{O}$ símbolo (a) denota as situações em que todas as correlações foram insatisfatórias. 
Os coeficientes cinemáticos de viscosidade turbulenta gerados pelos modelos de Prandle (1985) e de Fisher et al. (1972) apresentaram valores semelhantes entre si para todas as estações, com exceção da estação Mangue (Fig. 12); ambos modelos indicam que essa estação foi a que apresentou os maiores coeficientes, dentre as outras localidades amostradas ao longo do canal (Base Aérea, Marina, Itapanhaú e Barra).

Os aspectos mais importantes desses modelos são que ambos mostraram condições de maior cisalhamento vertical de $u$ nas estações Barra e Itapanhaú - sujeitas à influência direta da descarga de água doce do Rio Itapanhaú - refletidas em menores coeficientes, enquanto condições de menor cisalhamento da velocidade nas estações Marina e Mangue foram representadas por valores médios mais elevados.

Finalmente, em relação ao coeficiente cinemático de difusão turbulenta $\left(\mathrm{K}_{\mathrm{z}}\right)$, os resultados dos ajustes teoria-experimentação mostraram que, com as simulações do modelo de Fisher et al. (1972), foram obtidos valores relativamente baixos para os coeficientes de difusão turbulenta (Fig. 13) em todos os locais amostrados ao longo do canal. Entretanto, destaque deve ser dado aos maiores valores das estações Base Aérea e Mangue, que indicam a menor estratificação halina dentre os locais amostrados; esse padrão é reforçado pelo Diagrama Estratificação-circulação, pois os parâmetros estratificação obtido para essas estações foram os menores dentre todos.

Apesar da limitação física, expressa em baixas profundidades e larguras reduzidas, os coeficientes de mistura dessa região foram, em média, semelhantes aos estimados para a região de Cananéia. No Canal de Bertioga, a maré também teve participação ativa nos processos de mistura, sobretudo em épocas de sizígia.
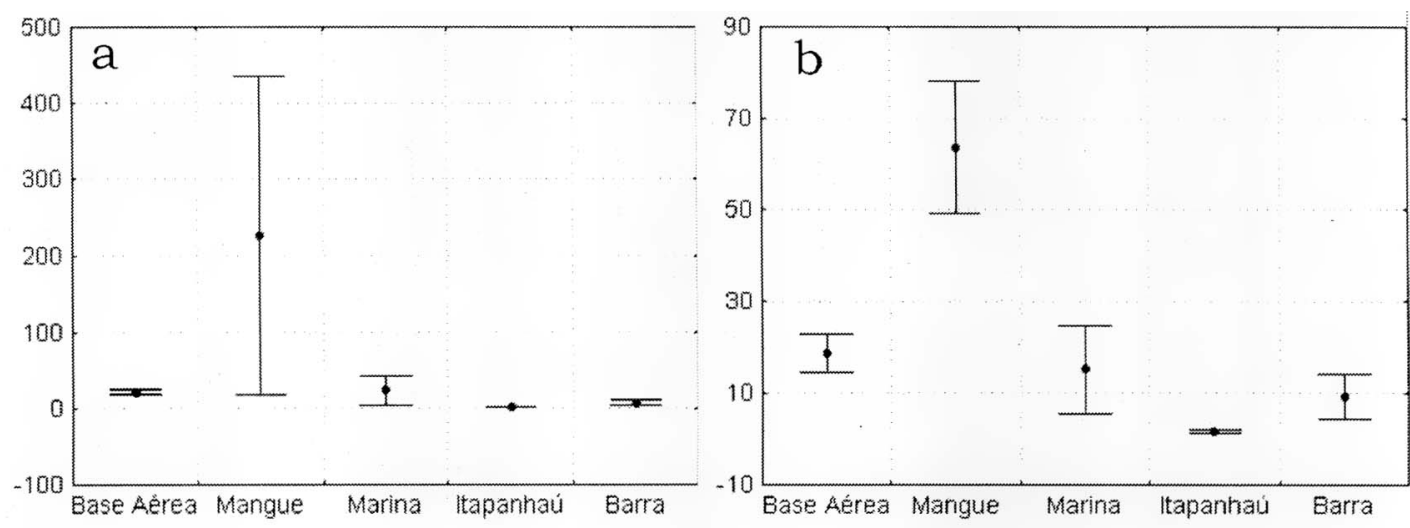

Fig. 12. Médias e desvios padrão dos coeficientes cinemáticos de viscosidade turbulenta $\mathrm{N}_{\mathrm{z}}$, em unidades de $10^{-4}$ $\mathrm{m}^{2} \mathrm{~s}^{-1}$, estimados para as estações de Bertioga a partir dos modelos de Prandle (1985) e Fisher et al. (1972), cujos resultados são indicados por $a$ e $b$, respectivamente.

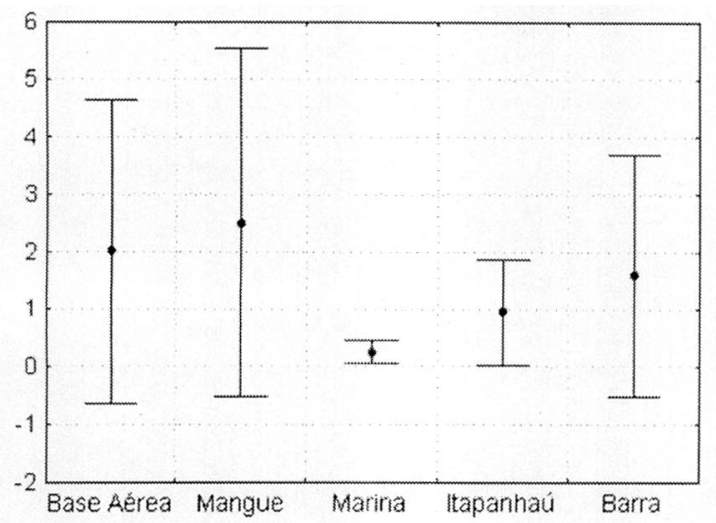

Fig. 13. Médias e desvios padrão dos coeficientes cinemáticos de difusão turbulenta $\mathrm{K}_{z}$, em unidades de $10^{-7} \mathrm{~m}^{2} \mathrm{~s}^{-1}$, estimados para as estações de Bertioga a partir do modelo de Fisher et al. (1972).

\section{Conclusões}

Nas duas regiões estudadas o efeito da modulação da maré, de acordo com a mudança da fase lunar, fez-se presente. Em virtude da semelhança da co-oscilação da maré em Cananéia e no Canal de Bertioga, as diferenças hidrodinâmicas mais evidentes entre essas áreas parecem estar relacionadas às variações da descarga fluvial $e$ às dimensões fisiográficas de cada um desses sistemas estuarinos. Em Cananéia, a descarga fluvial é pelo menos uma ordem de grandeza maior do que no Canal de Bertioga e comprimento, profundidade e a largura desses canais estuarinos assumiram importante papel na circulação e processos de mistura. Confirmando essas diferenças, os gradientes longitudinais de densidade, utilizados nos ajustes dos perfis teóricos aos experimentais na região de Cananéia, foram uma ordem de grandeza maiores do que os do Canal de 
Bertioga; sendo assim, a influência do componente baroclínico da força de gradiente de pressão foi maior no primeiro sistema.

A porção sul do Mar de Cananéia sofreu alterações significativas na circulação estacionária após o rompimento da barragem do Valo Grande, passando de condições bem misturadas com fraca estratificação (Tipo la) para parcialmente misturadas com alta estratificação (Tipo 2b) e predomínio da advecção nos processos de mistura. Os outros dois locais de coleta, Barra de Cananéia e Baía do Trapandé, também apresentaram condições de alta estratificação, sendo que no primeiro houve um equilíbrio entre a difusão turbulenta e a advecção nos processos de mistura e no segundo prevaleceu o processo advectivo.

O comportamento da velocidade nas estações amostradas na região sul do Sistema Estuarino-lagunar de Cananéia-Iguape, após o rompimento da barragem do Valo Grande, foi mais uniforme do que em Bertioga, onde foram observados perfis uni e bidirecionais de velocidade, enquanto na primeira predominaram as características bidirecionais. O Diagrama Estratificação-circulação reforça essa hipótese ao classificar todas as estações de Cananéia como Tipo 2 (parcialmente misturado), enquanto o Canal de Bertioga apresentou condições dos Tipos 1 e 2 (bem misturado e parcialmente misturado).

No Canal de Bertioga foi observada uma compartimentação nos padrões de circulação: as estações Barra e Itapanhaú foram parcialmente misturadas (Tipo 2a) com predomínio da difusão turbulenta nos processos de mistura enquanto as estações Marina, Mangue e Base Aérea apresentaram características mais próximas de condições verticalmente homogêneas (Tipo $1 b$ ).

Com a utilização de dois modelos analíticos (Fisher et al., 1972; Miranda, 1998) cuja circulação gravitacional foi forçada pela descarga fluvial, gradiente longitudinal de densidade e a tensão de cisalhamento do vento e um terceiro (Prandle, 1985) sem a influência do vento, foi possível identificar o gradiente longitudinal de densidade e a descarga fluvial como principais forçantes da circulação estacionária na região sul do Sistema Estuarinolagunar de Cananéia-Iguape e no Canal de Bertioga, em detrimento de uma influência secundária do vento, já que os valores teóricos de $u$ e $\mathrm{S}$ foram melhores ajustados aos experimentais considerando-se nulo o efeito da tensão de cisalhamento do vento. Para a região de Cananéia esse resultado foi concordante com trabalhos anteriores.

Os resultados teóricos gerados pelos modelos de Fisher et al. (1972), Prandle (1985) e Miranda (1998) foram, quali-quantitativamente, semelhantes entre si. Os ajustes das soluções teóricas aos dados experimentais de $\mathrm{S}$ e $u$ foram bastante satisfatórios, com exceção das condições de cisalhamento vertical pouco intenso $(\Delta \mathrm{u} / \Delta \mathrm{Z}<0,05$ $\left.\mathrm{m} \mathrm{s}^{-1}\right)$, cujas correlações inferiores a 0,6 foram estatisticamente rejeitadas. Nesses casos, a precisão do sensor de velocidade parece ter influenciado na determinação da configuração do perfil vertical de $u$.

Os coeficientes cinemáticos de viscosidade e difusão turbulentos das duas regiões, estimados com base nos ajustes dos resultados teóricos aos experimentais, tiveram ordens de grandeza semelhantes. As estações de Cananéia apresentaram valores um pouco superiores, o que indica para esta região menor cisalhamento vertical de velocidade e menor estratificação de salinidade e, por sua vez, melhores condições de mistura entre as águas de origem continental e as de origem marinha. No único caso em que pôde ser feita uma comparação entre os coeficientes experimentais e teóricos de viscosidade turbulenta, os resultados foram concordantes.

As diferenças encontradas entre as simulações teóricas perfis residuais de velocidade e de salinidade e os dados experimentais podem ser atribuídas às seguintes razões: i) valores constantes dos coeficientes cinemáticos de viscosidade turbulenta e de difusão turbulenta de sal, além das dificuldades decorrentes do ajuste simultâneo desses coeficientes na simulação dos perfis de salinidade; ii) a série temporal de dados não foi suficientemente longa para simulação de condições estacionárias; iii) os modelos analíticos foram deduzidos para estuários clássicos e geometria simples, e foram aplicados sistemas estuarinos complexos iv) a descarga fluvial foi estimada indiretamente a partir de trabalhos anteriores e o componente da velocidade gerada por essa descarga foi considerado igual à velocidade residual.

\section{Agradecimentos}

Àqueles que contribuíram ao longo dos experimentos, análise e elaboração dos resultados aqui apresentados, à tripulação dos barcos Veliger e Albacora, aos laboratórios de Micropaleontologia e de Dinâmica Oceânica do IOUSP, e aos revisores pelas contribuições. Especialmente à Coordenação de Aperfeiçoamento de Pessoal de Nivel Superior (CAPES) pela oferta de bolsa de estudos de Mestrado, e ao Conselho de Desenvolvimento Científico e Tecnológico (CNPq) pela concessão da Bolsa de Produtividade em Pesquisa ao segundo autor (Proc. 301014/79-5).

\section{Referências Bibliográficas}

Bérgamo, A. L. 2000. Características da hidrografia, circulação e transporte de sal: Barra de Cananéia, Sul do mar de Cananéia e Baía do Trapandé. M.Sc. Dissertation. Universidade de São Paulo, Instituto Oceanográfico. 214 p. 
Bernardes, M. E. C. 2001. Circulação estacionária e estratificação de sal em canais estuarinos parcialmente misturados: simulação com modelos analíticos. M.Sc. Dissertation. Universidade de São Paulo, Instituto Oceanográfico. 202 p.

Bonetti, J. F. 1995. Transporte de sedimentos por suspensão nas proximidades da Barra de Cananéia. M.Sc. Dissertation. Universidade de São Paulo, Instituto Oceanográfico. 2 v.

Bonetti, J. F. \& Furtado, V. V. 1996. Modelo digital de terreno aplicado ao estudo de feições costeiras submersas no litoral sul do Estado de São Paulo. Geociências, S Paulo,15(2):367-380.

Bonetti, J. F. \& Miranda, L. B. de. 1997. Estimativa da descarga fluvial no sistema estuarino-lagunar de Cananéia-Iguape. Rev. bras. oceanogr., 45(1/2):89-94.

Cameron, W. M. \& Pritchard, D. W. 1963. Estuaries. In: Hill, M. N. ed.. The Sea. Ideas and observations on progress in the study of the seas. New York, Interscience. p. 306-324.

DAEE - Departamento de Águas e Energia Elétrica. 1987. Contribuições superficiais dos rios que deságuam no sistema estuarino de IguapeCananéia (Mar Pequeno, Mar de Cubatão e Baía de Trapandé). Diretoria da Bacia do Ribeira e Litoral Sul/DAEE, OF/B.R.B./053/87.

Defant, A. 1960. Physical oceanography. Oxford, Pergamon Press. v. 2.

Eichler, P. P. B. 2001. Avaliação e diagnóstico do Canal de Bertioga (São Paulo, Brasil) através da utilização de foraminíferos como indicadores ambientais. Phd. Thesis. Universidade de São Paulo, Instituto Oceanográfico. 240p. + CD Rom.

Fisher, J. S.; Ditmars, J. D. \& Ippen, A. T. 1972. Mathematical simulation of tidal-time averages of salinity and velocity profiles in estuaries. Massachusetts, Rept. MITSG 72-11, M.I.T. $157 \mathrm{p}$.

Fúlfaro, V. J. \& Ponçano, W. L. 1976. Sedimentação atual do estuário e baía de Santos: um modelo geológico aplicado a projetos de expansão da zona portuária. In: CONGRESSO BRASILEIRO DE GEOLOGIA DE ENGENHARIA 1. Rio de Janeiro, 1976. Anais. Rio de Janeiro, ABGE, 2:67-90.

GEOBRÁS. 1966. Complexo Valo Grande, Mar pequeno, rio Ribeira de Iguape. São Paulo, Geobrás/DAEE. 2v.
Gianesella, S. M. F.; Saldanha-Corrêa, F. M. P. \& Teixeira, C. 2000. Tidal effects on nutrients and phytoplankton distribution in Bertioga Channel, São Paulo, Brazil. Aquatic Ecosystem Health and Management, 3:333-544.

Hansen, D. V. \& Rattray Jr., M. 1966. New dimensions in estuarine classification. Limnol. Oceanogr., 11(3):319-325.

Harari, J. \& Camargo, R. 1998. Modelagem numérica da região costeira de Santos (SP): circulação de maré. Rev. bras. oceanogr., 46(2):135-156.

Kjerfve, B. 1975. Velocity averaging in estuaries characterized by large tidal range to depth ratio. Estuar. coast. mar. Sci., 3:311-323.

Kjerfve, B. 1979. Measurement and analysis of water current, temperature, salinity and density. In: Dyer, K. R. ed. Estuarine hydrography and sedimentation. Cambridge, Cambridge University Press. p. 186-226.

Mesquita, A. R.; Miranda, L. B.; Furtado, V. V.; França, C. A. S.; Nonato, L. V. \& Vicentini, F. L. N. 1992. Medições de processos turbulentos na camada de contato do fundo oceânico e aplicação ao Estudo de transporte de sedimentos. Relatório. São Paulo, FAPESP.

Miranda, L. B. 1990. Sistemas estuarinos de planície costeira: estrutura dinâmica, processos de mistura e aplicações. In: SIMPÓSIO DE ECOSSISTEMAS DA COSTA SUL E SUDESTE BRASILEIRA, ESTRUTURA, FUNÇÃO E MANEJO, 2. Águas de Lindóia, 1990. Anais. São Paulo, ACIESP, 71(2):1-46.

Miranda, L. B. 1998. Cinemática e dinâmica de estuários. Notas de Aula do Curso de PósGraduação - IOF-827. Universidade de São Paulo, Instituto Oceanográfico. 469p.

Miranda, L. B.; Mesquita, A. R. \& França, C. A. S. 1995. Estudo da circulação e do processo de mistura no extremo sul do mar de Cananéia. Condições de dezembro de 1991. Bolm Inst. oceanogr., S Paulo, 43(2):153-164.

Miranda, L. B. \& Castro, B. M. 1991. Condições oceanográficas no Canal de Bertioga. Relatório Técnico. São Paulo, FUNDESPA. p. 1-97.

Miranda, L. B. \& Castro, B. M. 1996. On the salt transport in the Cananéia-sea during a spring tide experiment. Rev. bras. oceanogr., 44(2): $123-133$. 
Miranda, L. B. \& Castro, B. M. 1998. Aspectos físicos da pesquisa estuarina. In: SEMINÁRIO CIÊNCIA E DESENVOLVIMENTO SUSTENTÁVEL. São Paulo, USP, 1997. Anais. São Paulo, USP, 1998. p. 150-167.

Miranda, L. B.; Castro, B. M. \& Kjerfve, B. 1998. Circulation mixing due to tidal forcing in the Bertioga Channel, São Paulo, Brazil. Estuaries, 21(2):204-214

Mishima, M.; Yamanaka, N.; Pereira, O. M.; Soares, F. C.; Sinque, C.; Akaboshi, S. \& Jacobsen, O. 1985. Hidrografia do complexo estuarino-lagunar de Cananéia $\left(25^{\circ} \mathrm{S}, 048^{\circ} \mathrm{W}\right)$. São Paulo, Brasil. B. Inst. Pesca, 12(3):109-121.

Miyao, S. Y. 1977. Contribuição ao estudo da oceanografia física da região de Cananéia (lat. $25^{\circ} \mathrm{S}$ long. $\left.48^{\circ} \mathrm{W}\right)$. M.Sc. Dissertation, Universidade de São Paulo, Instituto Oceanográfico. 87p.

Miyao, S. Y.; Nishihara, L. \& Sarti, C. C. 1986. Características físicas e químicas do sistema estuarino-lagunar de Cananéia-Iguape. Bolm Inst. oceanogr., S Paulo, 34:23-36.
Miyao, S. Y. \& Harari, J. 1989. Estudo preliminar da maré e das correntes de maré na região estuarina de Cananéia $\left(25^{\circ} \mathrm{S}\right.$ e $\left.048^{\circ} \mathrm{W}\right)$. Bolm Inst. oceanogr., S Paulo, 37(2): 107-123.

Officer, C. B. 1977. Longitudinal circulation and mixing relations in estuaries. Estuaries, geophysics, and the environment. Washington, National Academy of Sciences. p. 13-21.

Prandle, D. 1985. On salinity regimes and the vertical structure of residual flows in narrow tidal estuaries. Estuar. coast. Shelf Sci., 20:615-635.

UNESCO. 1981. The practical salinity scale 1978 and the international equation of state of seawater 1980. UNESCO Tech. Pap. Mar. Sci., 36:25 p.

(Manuscrito recebido 28 março 2001; revisado 16 abril 2002; aceito 27 junho 2002) 